\title{
Biologic and clinical significance of androgen receptor variants in castration resistant prostate cancer
}

\author{
Kathryn E Ware ${ }^{1}$, Mariano A Garcia-Blanco ${ }^{1,2}$, Andrew J Armstrong ${ }^{1,2}$ and \\ Scott M Dehm ${ }^{3,4}$ \\ 'Departments of Molecular Genetics and Medicine, Duke University, 213 Research Dr, 0045 CARL Building, Durham, \\ North Carolina 27710, USA \\ ${ }^{2}$ Department of Medicine, Duke Cancer Institute, Duke University, Durham, North Carolina, USA \\ ${ }^{3}$ Masonic Cancer Center, University of Minnesota Masonic Cancer Center, Mayo Mail Code 806, \\ 420 Delaware Street SE, Minneapolis, Minnesota 55455, USA \\ ${ }^{4}$ Department of Laboratory Medicine and Pathology, University of Minnesota, Minneapolis, Minnesota, USA
}

\author{
Correspondence \\ should be addressed \\ to S M Dehm \\ Email \\ dehm@umn.edu
}

\begin{abstract}
As prostate cancer ( $\mathrm{PCa}$ ) progresses to the lethal castration resistant and metastatic form, genetic and epigenetic adaptation, clonal selection, and evolution of the tumor microenvironment contribute to the emergence of unique biological characteristics under the selective pressure of external stresses. These stresses include the therapies applied in the clinic or laboratory and the exposures of cancers to hormonal, paracrine, or autocrine stimuli in the context of the tumor micro- and macro-environment. The androgen receptor (AR) is a key gene involved in $\mathrm{PCa}$ etiology and oncogenesis, including disease development, progression, response to initial hormonal therapies, and subsequent resistance to hormonal therapies. Alterations in the AR signaling pathway have been observed in certain selection contexts and contribute to the resistance to agents that target hormonal regulation of the AR, including standard androgen deprivation therapy, antiandrogens such as enzalutamide, and androgen synthesis inhibition with abiraterone acetate. One such resistance mechanism is the synthesis of constitutively active AR variants lacking the canonical ligand-binding domain. This review focuses on the etiology, characterization, biological properties, and emerging data contributing to the clinical characteristics of AR variants, and suggests approaches to full-length $A R$ and $A R$ variant biomarker validation, assessment, and systemic targeting in the clinic.
\end{abstract}

Key Words

- androgen receptor

- splice variants

- castration resistant prostate cancer

- AR variants

- metastasis

- epithelial to mesenchymal transition

\section{Introduction}

Prostate cancer (PCa) is the most commonly diagnosed cancer and the second leading cause of cancer-related death in men (Siegel 2013). Many of these men are diagnosed with an indolent form of the disease and are candidates for active surveillance rather than immediate therapy, while a minority of men are diagnosed with highgrade, high-risk disease requiring aggressive surgery, radiation, and hormonal therapy approaches. As a result, the risk of death due to $\mathrm{PCa}$ is much lower (one in 30) than the risk of being diagnosed with PCa (one in six) and there is an unmet need to identify those who will progress to aggressive disease through the development of predictive biomarkers. For PCa that has disseminated or recurred following primary therapies, current systemic treatments are able to control the disease often for many years. However, the lethal form of metastatic PCa remains an 
important public health problem, contributing to over 80 deaths per day in the US.

The androgen receptor (AR) has been identified as an important contributor to the etiology and progression of PCa as well as to the initial response and subsequent resistance to endocrine therapies such as androgen deprivation therapy (ADT). AR is a nuclear hormone receptor comprising eight exons that make up four functional domains including the $\mathrm{NH}_{2}$-terminal domain (NTD, exon 1), the DNA-binding domain (DBD, exons 2 and 3 ), the hinge region (the $3^{\prime}$ portion of exon 3 and the $5^{\prime}$ portion of exon 4 ), and the-ligand-binding domain (LBD, the remainder of exon 4-8) (Fig. 1B). The LBD binds androgens, leading to the exposure of the nuclear localization signal (NLS) in the hinge region of AR and the translocation of AR to the nucleus. In the nucleus, the DBD is important for recognizing and binding androgen-response elements (AREs) in the promoters and enhancers of AR transcriptional targets. When bound to DNA, the AR NTD accounts for the majority of AR transcriptional activity through interactions with co-regulators.

The androgen/AR axis drives male development, including the genesis and differentiation of the prostate gland. In adult males, the androgen/AR axis continues to be critical for normal prostate gland function. This tissue developmental basis for androgen/AR dependence is also a fundamental property of PCa cells (Garraway \& Sellers 2006). AR dependence in PCa cells is further reinforced by AR shaping the 3-dimensional architecture of chromatin in the nucleus, enhancing certain inter- and intra-chromosomal interactions that can result in the generation of specific oncogenic fusion proteins that often become androgen regulated (Lin et al. 2009, Mani et al. 2009, Haffner et al. 2010, Berger et al. 2011, Weischenfeldt et al. 2013). For example, fusion of the androgen-regulated TMPRSS2 promoter with the coding region of the erythroblast transformation-specific (ETS)related gene (ERG) transcription factor leads to high-level, androgen-driven overexpression of ERG. These critical roles for AR in maintaining the prostate tissue lineage, as well as expression of the PCa genome, are the likely basis for the effectiveness of ADT, which is achieved through orchiectomy or chemically with gonadotropin-releasing hormone agonists or antagonists, followed by treatment with antiandrogens or combination approaches. However, despite most men having favorable initial responses to ADT, progression to castration-resistant disease is nearly universal over time. While some men with metastatic disease progress within 1 year of ADT, other men respond 5 or more years, illustrating the clinical heterogeneity in AR targeting (Hussain et al. 2006), and heterogeneity in survival is even greater in the non-metastatic setting (Freedland et al. 2007).
PCa progression on ADT does not typically occur through the mechanisms of bypassing androgen or AR dependence, as evidenced by studies demonstrating the importance of autocrine androgen synthesis and AR protein overexpression for castration-resistant $\mathrm{PCa}$ (CRPC; Chen et al. 2004, Stanbrough et al. 2006). Aberrant AR transcriptional activity in CRPC can occur due to amplification of the $A R$ gene leading to protein overexpression (Chen et al. 2004), mutations in the $\mathrm{NH}_{2}$-terminal domain, or LBD that render the receptor more sensitive to androgen activation (Han et al. 2001), or induce inappropriate agonist responses to antagonists such as bicalutamide or enzalutamide (Balbas et al. 2013, Joseph et al. 2013, Korpal et al. 2013). In addition, the de novo autocrine synthesis of androgens by the tumor itself can occur through overexpression of key androgenic metabolic enzymes such as CYP17A1, AKR1C3, HSD3B2, CYP11A1, and SRD5A1 and 2 (Mostaghel et al. 2011), or through mutational activation of these enzymes, such as the recently described protein-stabilizing mutation in HSD3B2 (Chang et al. 2013). Finally, ligand-independent AR activity is modulated by post-translational modifications, including phosphorylation, SUMOlyation, methylation, ubiquitination, and acetylation. Each of these protein modifications is regulated by upstream oncogenic events and may converge on the AR to support persistent activity (Coffey \& Robson 2012).

Further evidence of sustained AR activity was demonstrated by the responsiveness and survival benefits observed with newer AR-targeted agents such as enzalutamide and abiraterone acetate, which were developed to more potently inhibit AR signaling in the face of castrate levels of testosterone (Scher et al. 2010, 2012, de Bono et al. 2011, Ryan et al. 2013). Abiraterone acetate is a CYP17 hydroxylase and lyase inhibitor, which partially inhibits androgen synthesis in the adrenal gland, testes, and tumor tissue. Abiraterone increased overall survival from 10.9 to 14.8 months in the post-docetaxel metastatic CRPC setting (de Bono et al. 2011), and delayed progression or death by over 8 months in the pre-chemotherapy metastatic CRPC setting (Ryan et al. 2013). Enzalutamide binds AR with higher affinity than do conventional antiandrogens and impairs AR nuclear localization and transcriptional activity even under conditions of AR overexpression (Tran et al. 2009, Clegg et al. 2012). Enzalutamide increased median overall survival from 13.6 months in the placebo group to 18.4 months in the enzalutamide group in the postdocetaxel metastatic CRPC setting (Scher et al. 2012), and a phase 3 trial in the pre-docetaxel metastatic CRPC setting has been completed with results anticipated soon.

Published by Bioscientifica Ltd. 


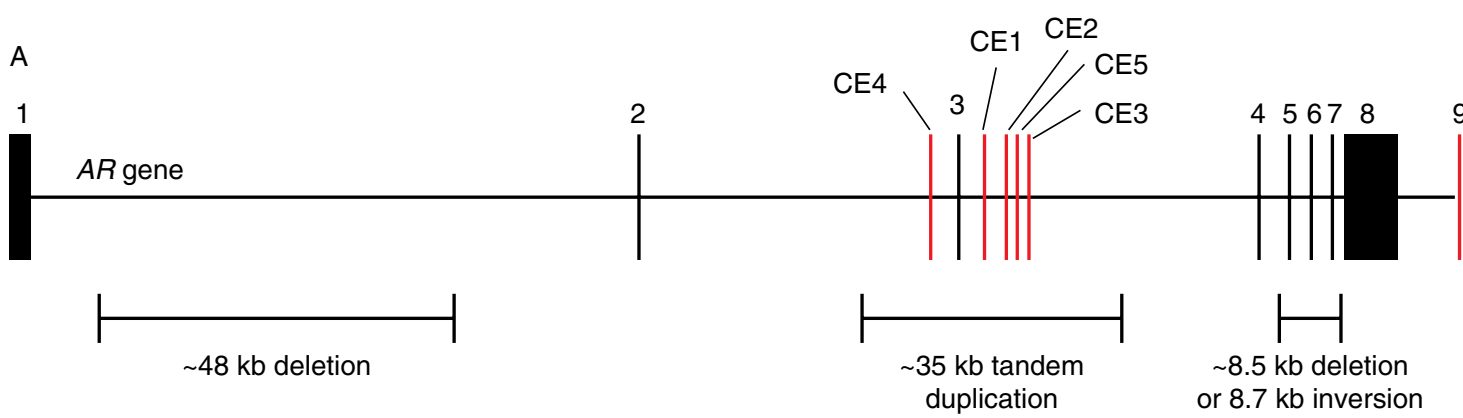

B

\begin{tabular}{|c|c|c|c|c|c|c|c|c|c|}
\hline & 1 & 2 & 3 & 4 & 5 & 6 & 7 & GIIIIIIIIIIIIII, $A_{n}$ & Full-length AR \\
\hline $5^{\prime} \cup 7$ & NTD & DBL & & Hinge & & LE & & 3'UTR & \\
\hline
\end{tabular}

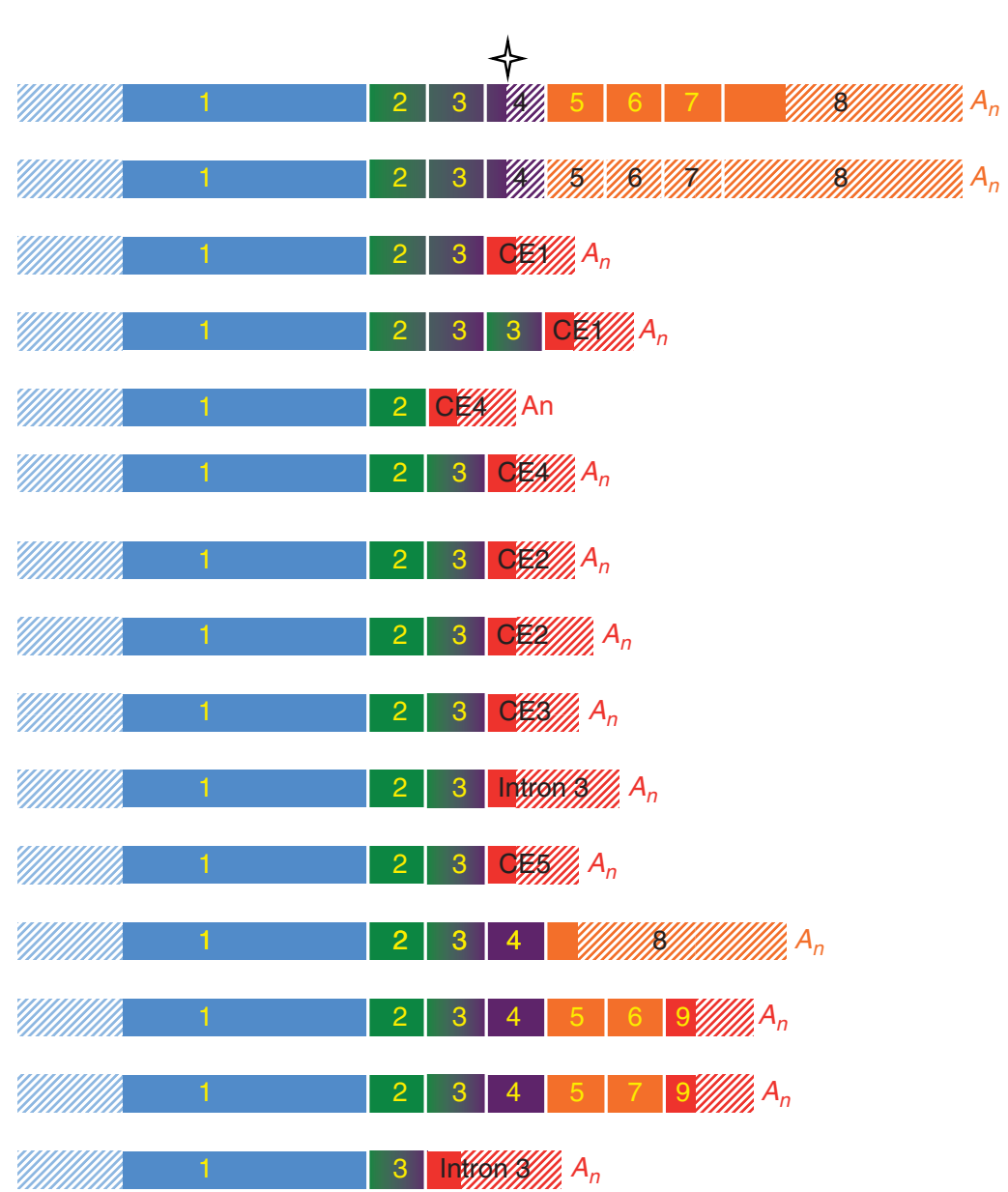

Alternative

AR-variants names

trAR

ARQ640X

AR-V1

AR4

AR-V2

AR-V3

AR1/2/2b

AR-V4 AR1/2/3/2b

AR5

AR-V5

AR-V6

AR-V7

AR3

AR-V8, AR-V10

AR-V11

AR-V9

AR-V12 AR ${ }^{\text {V567es }}$

AR-V13

AR-V14

AR-V15

AR8

\section{Figure 1}

$A R$ gene rearrangements and $A R$ variants identified in prostate cancer. (A) Schematic of $A R$ gene mutations and genomic alterations with cryptic exons indicated in red. (B) Schematic of AR and variant mRNA. Functional domains represented as $\mathrm{NH}_{2}$-terminal domain (NTD) in blue, DNA-binding domain (DBD) in green, hinge region in purple, and ligand-binding domain
(LBD) in orange. Cryptic exons are colored red. Solid regions represent the open reading frame. Star indicates calpain recognition site for proteolytic cleavage. Distinct AR variants AR-V8, AR-V10, and AR-V11 are represented by one schematic.

Published by Bioscientifica Ltd 
The greater activity of these agents when used earlier in the disease suggests the relative importance of these endocrine/autocrine resistance mechanisms in early CRPC development.

However, despite the initial striking response to these next generation AR-targeted agents in the clinic, resistance develops typically within 1-2 years in nearly all men with metastatic CRPC, as evidenced by rises in prostate-specific antigen (PSA) or radiographic and symptomatic signs of progressive tumor growth or dissemination. Mutations in $A R$ leading to enzalutamide agonism suggest that the selection pressure of potent AR inhibition leads to tumor adaptation or selection of clones able to persist despite enzalutamide (Balbas et al. 2013, Joseph et al. 2013, Korpal et al. 2013). These data also suggest the central importance of AR in CRPC biology, given that this selection pressure and emergence of resistant mutations would not be expected to occur if AR was not a central regulator of $\mathrm{PCa}$ survival at least in some men with CRPC. While the cell of origin in human PCa is debated and may be heterogeneous in different contexts (Wang et al. 2009, 2013, Goldstein et al. 2010, Choi et al. 2012), these data suggest that AR plays an important role in regulating the survival of the bulk of PCa cells in many patients. In addition, crossresistance is commonly observed between enzalutamide and abiraterone acetate in the clinic (Loriot et al. 2013, Noonan et al. 2013, Schaeffer 2013). This 'one and done' nature of treatment response suggests that there are underlying mechanisms of resistance to both agents that limit subsequent treatment with the other. This crossresistance is likely mediated at least in part by alterations in AR structure and function, given that progressive disease is typically accompanied by continued rises in serum levels of PSA, an AR-regulated gene. In further support of this, multiple constitutively active AR variants have been shown to be expressed in CRPC. These AR variants lack the AR LBD, the domain through which conventional ADT, abiraterone, and enzalutamide all exert their inhibitory actions. However, the precise role of AR variants in the mediation of PCa progression is still being deliberated. Herein, we will review the accumulating evidence pertaining to AR variant characterization, biologic properties, emergence in the clinic, and the clinical implications of $A R$ variants in mediating lethal CRPC.

\section{Origin of AR variants in PCa}

Over the past decade, 17 AR variants that lack the ligandbinding domain have been discovered in PCa cell lines (22Rv1, VCaP, and CWR-R1), human xenografts
(LuCaP 86.2, LuCaP136), and clinical PCa specimens. AR variants share a common core NTD/DBD structure encoded by contiguously spliced AR exons 1, 2, and 3, but differ at their $\mathrm{COOH}$-terminal end by virtue of being encoded by mRNAs with different $3^{\prime}$ terminal exons (Fig. 1B). The most striking feature of AR variants is the lack of the LBD, which strongly suggests they play a role in PCa progression and resistance to therapies targeted at this domain. Of the $17 \mathrm{AR}$ variants that have been reported, ten have been reliably detected by RT-PCR in PCa specimens (Table 1). However, the levels of certain AR variants in these clinical specimens appear to be highly variable, and are usually lower than in the cell lines and xenograft models in which they were originally discovered (Ceraline et al. 2003, Dehm et al. 2008, Guo et al. 2009, Hu et al. 2009, 2011, Sun et al. 2010, Watson et al. 2010, Yang et al. 2011, Zhang et al. 2011; Table 1). Several mechanisms for the synthesis of AR variants have been identified, including proteolytic cleavage of full-length AR, genomic alterations/mutations, and alternative or altered splicing. These mechanisms are discussed in detail below.

\section{Proteolytic cleavage}

An AR variant termed trAR was shown to result from cleavage by calpains (calcium-dependent proteinases) (Libertini et al. 2007). Calpains can cleave the full-length AR protein in the hinge region between amino acids 648 and 649 and generate two polypeptides: an 80-kDa protein consisting of the NTD, DBD, and hinge domains, and a second protein containing the LBD. 22Rv1 is an androgenindependent cell line derived from the androgendependent parent CWR22 tumor xenograft and is the cell line in which an AR variant protein lacking the LBD was first discovered (Tepper et al. 2002). Treatment of 22Rv1 cells with a calpain inhibitor reduced AR variant expression and re-sensitized cells to ADT (Libertini et al. 2007), indicating that trAR synthesis is partially calpaindependent, post-translationally regulated, and important for androgen independence. Further, calpain expression was increased in metastatic PCa (Rios-Doria et al. 2004), but there is no direct evidence of calpain-mediated AR variant synthesis in PCa specimens.

\section{Point mutations and genomic rearrangements}

An early study used a yeast-based functional assay to detect and analyze mutant ARs in PCa. In this study, Ceraline et al. discovered a nonsense mutation located in exon 4, Q640X, that creates a premature stop codon,

Published by Bioscientifica Ltd. 
Table 1 Characteristics and expression differences of AR variants

\begin{tabular}{|c|c|c|c|c|c|c|}
\hline \multirow[b]{2}{*}{ AR variant } & \multirow[b]{2}{*}{$\begin{array}{l}\text { Splice } \\
\text { junction }\end{array}$} & \multirow[b]{2}{*}{ Activity } & \multicolumn{2}{|c|}{ Expression } & \multirow[b]{2}{*}{$A R$ genomic alterations } & \multirow[b]{2}{*}{ Ref. } \\
\hline & & & $\begin{array}{l}\text { Human } \\
\text { CRPC tissue }\end{array}$ & Cell line & & \\
\hline $\operatorname{trAR}$ & 648 a.a. & Constitutive & & $22 \mathrm{Rv} 1$ & $\begin{array}{l}35 \mathrm{~kb} \text { tandem } \\
\text { duplication (exon } 3 \text { ) }\end{array}$ & Libertini et al. (2007) \\
\hline ARQ640X & $1 / 2 / 3 / 4$ & Constitutive & mRNA & & Point mutation & Ceraline et al. (2003) \\
\hline$A R-V 1$ & 3/CE1 & Conditional & mRNA & VCaP & Amplification & $\begin{array}{c}\text { Guo et al. (2009) and } \\
\text { Hu et al. (2009) }\end{array}$ \\
\hline$A R-V 2$ & 3/3/CE1 & NA & & $22 \mathrm{Rv} 1$ & $\begin{array}{l}35 \mathrm{~kb} \text { tandem } \\
\text { duplication (exon } 3 \text { ) }\end{array}$ & $\begin{array}{c}\text { Guo et al. (2009) and } \\
\text { Hu et al. (2009) }\end{array}$ \\
\hline AR-V3 & 2/CE4 & Constitutive & & $22 \mathrm{Rv} 1$ & $\begin{array}{l}35 \mathrm{~kb} \text { tandem } \\
\text { duplication (exon } 3 \text { ) }\end{array}$ & $\begin{array}{c}\text { Dehm et al. (2008) and } \\
\text { Hu et al. (2009) }\end{array}$ \\
\hline AR-V4 & 3/CE4 & Constitutive & & $22 R v 1$ & $\begin{array}{l}35 \mathrm{~kb} \text { tandem } \\
\text { duplication (exon } 3 \text { ) }\end{array}$ & $\begin{array}{l}\text { Dehm et al. (2008), } \\
\text { Guo et al. (2009) and } \\
\text { Hu et al. (2009) }\end{array}$ \\
\hline AR-V5 & 3/CE2 & NA & mRNA & 22Rv1 & $\begin{array}{l}35 \mathrm{~kb} \text { tandem } \\
\text { duplication (exon } 3 \text { ) }\end{array}$ & Hu et al. (2009) \\
\hline AR-V6 & 3/CE2 & NA & mRNA & $22 R v 1$ & $\begin{array}{l}35 \mathrm{~kb} \text { tandem } \\
\text { duplication (exon } 3 \text { ) }\end{array}$ & Hu et al. (2009) \\
\hline \multirow[t]{4}{*}{ AR-V7 } & 3/CE3 & Constitutive & $\begin{array}{l}\text { mRNA, } \\
\text { protein }\end{array}$ & LNCAP95 & & $\begin{array}{c}\text { Guo et al. (2009) and } \\
\text { Hu et al. (2009) }\end{array}$ \\
\hline & & & & VCaP & Amplification & \\
\hline & & & & 22Rv1 & $\begin{array}{l}35 \mathrm{~kb} \text { tandem } \\
\text { duplication (exon } 3 \text { ) }\end{array}$ & \\
\hline & & & & CWR-R1 & $\begin{array}{l}48 \mathrm{~kb} \text { deletion } \\
\text { (intron 1) }\end{array}$ & \\
\hline AR-V8 & 3/intron 3 & NA & & VCaP & Amplification & Watson et al. (2010) \\
\hline AR-V9 & 3/CE5 & Conditional & mRNA & VCaP & Amplification & $\begin{array}{l}\text { Watson et al. (2010) and } \\
\text { Hu et al. (2011) }\end{array}$ \\
\hline AR-V10 & 3/intron 3 & NA & & VCaP & Amplification & Watson et al. (2010) \\
\hline AR-V11 & 3/intron 3 & NA & & VCaP & Amplification & Watson et al. (2010) \\
\hline \multirow[t]{4}{*}{$\begin{array}{l}A R-V 12 / \\
A R^{\text {v567es }}\end{array}$} & 4,8 & Constitutive & mRNA & LuCaP 86.2 & $\begin{array}{r}8.5 \text { kb deletion } \\
(\text { exon } 5,6,7)\end{array}$ & $\begin{array}{c}\text { Sun et al. (2010) and } \\
\text { Hu et al. (2011) }\end{array}$ \\
\hline & & & & LuCaP 136 & $\begin{array}{l}\text { 8.7 kb inversion } \\
(\text { exon } 5,6,7)\end{array}$ & \\
\hline & & & & 22Rv1 & $\begin{array}{l}35 \mathrm{~kb} \text { tandem } \\
\text { duplication (exon } 3 \text { ) }\end{array}$ & \\
\hline & & & & VCaP & Amplification & \\
\hline AR-13 & 6,9 & Negative & mRNA & & & Hu et al. (2011) \\
\hline AR-V14 & 7,9 & NA & mRNA & & & Hu et al. (2011) \\
\hline \multirow[t]{4}{*}{ AR8 } & 1/3/intron 3 & Increases & mRNA & C4-2 & & Yang et al. (2011) \\
\hline & & phosphorylation & & C4-2B & & \\
\hline & & of full-length AR & & CWR22 & & \\
\hline & & & & CWR-R1 & $\begin{array}{l}48 \text { kb deletion } \\
\quad \text { (intron 1) }\end{array}$ & \\
\hline
\end{tabular}

Constitutive, ligand-independent nuclear localization and activity; Conditional, cell line- or promoter-specific ligand-independent nuclear localization and activity; Negative, no ligand-independent localization or activity; NA, not assessed.

leading to synthesis of a constitutively active AR variant protein that localizes to the nucleus (Ceraline et al. 2003, Bergerat \& Ceraline 2009). More recently, genomic alterations within the $A R$ gene have been shown to generate AR variants (Li et al. 2011, 2012, Nyquist et al. 2013). The first genomic alteration (a $35 \mathrm{~kb}$ tandem duplication encompassing exon 3 and flanking cryptic exons) (Fig. 1A) was discovered in 22Rv1 cells (Li et al. 2011). Although calpain-mediated proteolysis was thought to be the primary mechanism leading to AR variant expression in 22Rv1, multiple subsequent studies have shown that altered splicing is the dominant force. The discovery of this $35 \mathrm{~kb}$ tandem duplication in 22Rv1 provided a rational basis for the altered splicing observed in these cells. Importantly, culture of CWR22Pc cells (an androgen-dependent cell line derived from the original CWR22 xenograft) in androgen-depleted media led to the detection of the $35 \mathrm{~kb}$ tandem duplication in

Published by Bioscientifica Ltd 
the $A R$ gene and expression of AR variant protein. This suggests that expression of AR variants in CWR22Pc cells is limited to those cells harboring the genetic duplication and that these genomic alterations cause variations in AR splicing. Indeed, AR intragenic rearrangements have also been defined in human xenograft models LuCaP 86.2 and LuCaP 136 (8.5 kb deletion or $8.7 \mathrm{~kb}$ inversion including exons 5-7) (Fig. 1A), which both express high levels of the AR-V12/AR ${ }^{\text {v567es }}$ variant lacking exons 5, 6, and 7 (Li et al. 2012, Nyquist et al. 2013). Interestingly, these gene rearrangements in LuCaP 86.2 and 136 result in $A R$ gene structures that can only produce AR variant. It is also noteworthy that $A R$ gene rearrangements do not always encompass alternatively spliced exons. For example, a $48 \mathrm{~kb}$ deletion located in intron 1 of the $A R$ gene was identified in a sub-population of cells in the CWR-R1 cell line. CWR-R1 cells express high levels of AR-V7 arising from exon 3 splicing to the cryptic exon CE3 located in AR intron 3 (Li et al. 2012; Fig. 1B). Because the 'alternatively spliced' exon CE3 is not directly affected by the $A R$ gene rearrangement in these cells, it is not immediately clear how this genomic event could favor AR-V7 synthesis. However, there appears to be a direct link between the CWR-R1 cell population harboring this deletion and altered AR splicing. For instance, long-term culture of CWR-R1 cells under castrate conditions leads to the outgrowth of the sub-population harboring the AR intron 1 deletion as well as increased expression of AR-V7. In addition, single cell cloning demonstrated that high-level AR-V7 expression was restricted to cells positive for this deletion (Li et al. 2013). Together, these data indicate that distant changes in the $A R$ genomic architecture can cause splice switches that favor the expression of AR variants.

The mechanism for genomic rearrangements is thought to be induced by the structural architecture associated with the local genomic region (Gu et al. 2008). The $A R$ intragenic duplications, deletions, and inversions identified in PCa contain signatures of microhomologymediated break-induced replication (MMBIR) or non-homologous end joining (NHEJ) at break fusion junction sites (Li et al. 2011, 2012, Nyquist et al. 2013). The presence of long interspersed nuclear elements (LINE1) flanking the fusion, microhomology at the breakpoint, and inserted sequence at the fusion in $22 \mathrm{Rv} 1$ cells is the trademark for MMBIR mechanisms (Hastings et al. 2009). The diverse genomic architecture of the proximal arm of the X chromosome is characterized by a high concentration of recombinogenic structures that can form hairpins and cruciforms and render it ideal for replication-based rearrangements; thus, leading to complex somatic rearrangements seen in cancer. Furthermore, MMBIR and NHEJ catalyze non-recurrent breakpoints (Koumbaris et al. 2011). Therefore, the exact locations of AR breakpoints are expected to vary between patient specimens giving intrinsic genomic heterogeneity.

The functional significance of $A R$ genomic alterations was addressed in a study implementing transcription activator-like effector nuclease (TALEN) genome engineering to model the rearrangements observed in LuCaP 86.2 and LuCaP 136. TALENs are synthetic fusion proteins consisting of a nonspecific DNA-cleaving nuclease and a DBD that is engineered to target a sequence of interest (Joung \& Sander 2013). Using TALENs targeted to exons 4 and 7 , cell lines were generated with deletion or inversion events comprising AR exons 5-7, thus modeling the rearrangements naturally occurring in LuCaP 86.2 and LuCaP 136 xenografts. These engineered rearrangements produced cells that expressed AR-V12/AR ${ }^{\mathrm{v} 567 \text { es }}$ exclusively, thereby creating the first AR variant-dependent model that is completely androgen-independent. Further, in a heterogeneous cell population, ADT enriched the growth of cells containing the $A R$ deletion or inversion. Importantly, AR-V12/AR ${ }^{\mathrm{v} 567 e s}$ was able to maintain constitutive activity of the AR transcriptional program. This investigation was the first to verify that the $A R$ gene rearrangements encompassing exons 5-7 are causal events that lead to expression of $\mathrm{AR}-\mathrm{V} 12 / \mathrm{AR}^{\mathrm{v} 567 \mathrm{es}}$ and that a constitutively active AR variant is capable of sustaining the AR transcriptional program in an endocrine-independent manner.

\section{Alternative splicing}

It is clear from the studies discussed above that rearrangements in the $A R$ gene underlie splice switches that lead to the synthesis of AR variants; however, other reports indicate that AR variants can also be induced rapidly in response to ADT. Ligand-bound AR binds to an ARE located in intron 1 of the $A R$ gene and recruits repressive lysine-specific demethylase activity, leading to AR-mediated feedback inhibition of AR transcriptional activity. ADT relieves this feedback inhibition, increasing AR transcriptional output and expression of full-length AR and possibly AR variants (Cai et al. 2011). In line with this, a series of preclinical studies demonstrated that AR-V7 mRNA expression is rapidly upregulated subsequent to ADT and can be reversed when full-length AR signaling is reactivated (Watson et al. 2010, Hu et al. 2012). These data indicate that AR-V7 expression is acutely and reversibly regulated, perhaps by the way of androgen-regulated changes in $\mathrm{AR}$ transcriptional output, AR alternative

Published by Bioscientifica Ltd. 
splicing, or both. The rapid reversibility of these reactions suggests that expression of AR-V7 in this case cannot be accounted by clonal selection of cell populations with $A R$ gene rearrangements.

The importance of $\mathrm{AR}$ transcriptional elongation rates for increased AR-V7 expression was recently demonstrated by Liu et al., who detected increased expression of both full-length AR and AR-V7 following ADT. Higher $A R$ transcription rates were required to increase the recruitment of the necessary splicing factors for global increases in mature $A R$ mRNA species. The authors concluded that ADT enhances $A R$ transcription, which leads to increased AR pre-mRNA that is processed through splicing to generate mRNAs encoding AR-V7 as well as full-length AR. Importantly, this study also identified two cis-acting elements (one intronic splicing enhancer and one exonic splicing enhancer) near the $3^{\prime}$ splice site of AR exon CE3 (also referred to as AR exon $3 b$, the cryptic exon spliced to exon 3 in AR-V7, see Fig. 1B) and the respective trans-acting binding proteins (U2AF2 and SFRS1) (Liu et al. 2013b). The mechanism by which these splicing factors increase association with the $A R$ mRNA following ADT is not known. They are unlikely to be the direct transcriptional targets of AR variants as there was no change in their expression after treatment. To date, this is the only study analyzing plasticity in AR variant expression via an alternative splicing mechanism. Future effort is needed to address whether these splice factors are important for the splicing of other AR variants and whether these cis- and trans-factors are important in the context of $A R$ gene rearrangements occurring in cell lines, tumor xenografts, and clinical CRPC specimens. In cells such as CWR-R1, where large $A R$ gene rearrangements occur but all AR exons are present in their normal order, it will be important to understand the role of the splicing machinery in recognizing alternative splice sites and supporting AR variant synthesis. Also, additional cis-acting elements and transacting factors need to be mapped and identified for the additional cryptic exons that have been shown to splice into $A R$ mRNAs and lead to the synthesis of other AR variants.

Overall, these studies have demonstrated that diverse genetic and epigenetic mechanisms can mediate expression of AR variants, leading to androgen-independent activation of the AR pathway. Cells with $A R$ gene rearrangements display stable and efficient synthesis of AR variants ( $\mathrm{Li}$ et al. 2011, 2012). In contrast, cells that regulate AR variants acutely in response to ADT express much lower levels of AR variant compared with full-length AR (Watson et al. 2010, Hu et al. 2012). Based on these considerations, it is tempting to speculate that AR variants are synthesized acutely to survive ADT conditions, and that the $A R$ gene is a hotspot for genomic rearrangements eventually selecting for arrangements that can support stable, efficient synthesis of AR variants and promote PCa progression. In addition, the prevalence and abundance of AR variants are likely context dependent, varying and increasing over time as PCa progresses from localized disease to metastatic disease to CRPC and eventually to enzalutamide/abiraterone refractory metastatic CRPC.

\section{Role of AR variants in CRPC progression}

\section{Preclinical models}

Previous studies demonstrated that the specific knockdown of endogenous AR variants in androgenindependent cell lines, 22Rv1 and CWR-R1, was sufficient to inhibit both in vitro and in vivo growth under castrate conditions (Guo et al. 2009, Li et al. 2012), as well as restore cell responsiveness to androgens and enzalutamide (Li et al. 2013). In addition, overexpression of AR variants was sufficient to drive growth during ADT in androgendependent LNCaP cells (Dehm et al. 2008, Guo et al. 2009, Sun et al. 2010, Chan et al. 2012). However, there have been conflicting reports as to whether AR variants provide an overall growth advantage, or are only advantageous to tumor cells under hormone-depleted conditions. On one hand, xenografts of LNCaP cells expressing the AR-V12/AR ${ }^{\text {v567es }}$ variant grew larger than LNCaP xenografts alone, but only after castration (Sun et al. 2010). Conversely, a genomic mouse model engineered to express $\mathrm{AR}-\mathrm{V} 12 / \mathrm{AR}^{\mathrm{v} 567 \mathrm{es}}$ only in prostate epithelium demonstrated that both sham and castrated mice had a significant increase in genitourinary (GU) and prostate weight compared with WT controls. This indicates that AR-V12/AR ${ }^{\mathrm{v} 567 e s}$ can support higher proliferative rates in the prostate epithelium even before castration-induced ADT, likely by augmenting full-length AR activity. On the other hand, the function of AR-V12/AR ${ }^{\mathrm{v} 567 \mathrm{es}}$ in advanced progression to adenocarcinoma is more pronounced in castrated AR-V12/AR ${ }^{\mathrm{v} 567 e s}$ mice compared with shamtreated AR-V12/AR ${ }^{\mathrm{v} 567 \mathrm{es}}$ mice (Liu et al. 2013a). In an AR-V7 genetically engineered mouse model, mice expressing AR-V7 had impaired prostate regeneration after re-administration of testosterone following castration (Sun et al. 2013). These data suggest that AR variants may have a functional role in normal prostate epithelium that is deregulated when the expression of AR variants is selected for during ADT, or that ADT itself regulates a set of genes that alter AR variant activity and function.

Published by Bioscientifica Lto. 
Table 2 Clinical and biological relevance of AR variants

\begin{tabular}{|c|c|c|c|}
\hline Variant & Clinical relevance & Biological relevance & Refs. \\
\hline AR-V7 & $\begin{array}{l}\text { Enriched in HRPC and metastasis, } \\
\text { high risk of recurrence, decreased } \\
\text { overall survival }\end{array}$ & $\begin{array}{l}\text { Resistant to ADT, resistant to } \\
\text { enzalutamide, induces EMT }\end{array}$ & $\begin{array}{l}\text { Guo et al. (2009), Hu et al. (2009), } \\
\text { Sun et al. (2010), Watson et al. } \\
\text { (2010) and Cottard et al. (2013) }\end{array}$ \\
\hline AR-V12/AR ${ }^{\mathrm{v} 567 e s}$ & Enriched in HRPC and metastasis & $\begin{array}{l}\text { Resistant to ADT, drives invasive } \\
\text { adenocarcinoma in vivo }\end{array}$ & $\begin{array}{l}\text { Sun et al. (2010) and Liu et al. } \\
\quad(2013 b)\end{array}$ \\
\hline AR-V1 & Enriched in HRPC and metastasis & Not resistant to ADT & $\begin{array}{l}\text { Hu et al. (2009), Watson et al. (2010) } \\
\text { and Hornberg et al. (2011) }\end{array}$ \\
\hline
\end{tabular}

HRPC, hormone-refractory prostate cancer; ADT, androgen deprivation therapy; EMT, epithelial-to-mesenchymal transition.

Given that high AR variant expression in bone metastases is associated with shorter time to death in men with metastatic CRPC (Hornberg et al. 2011), and that high levels of AR variant expression in localized tumors is associated with disease recurrence (Guo et al. 2009), AR variant expression is likely to be important across the disease spectrum of aggressive $\mathrm{PCa}$, particularly during ADT resistance (Fig. 2C and D).

\section{Clinical impact of AR variant emergence}

Studies of AR variants in the clinic are limited by the lack of clinically validated assays for individual AR variant detection using specific antibodies and the dearth of large metastatic tissue repositories linked to CRPC outcomes. Despite these limitations, which are currently being addressed, current evidence suggests that AR variants may be functional drivers of PCa progression (Guo et al. 2009, Hu et al. 2009, 2011, Sun et al. 2010, Hornberg et al. 2011, Zhang et al. 2011). Hu et al. (2009) focused on AR-V1 and AR-V7 expressions and found an average 20-fold higher expression of variant mRNA in CRPC $(n=25)$ than in hormone-naïve $(\mathrm{HN}) \mathrm{PCa}(n=82, P<0.0001)$. AR-V7 mRNA, but not AR-V1 mRNA, predicted biochemical recurrence following surgical treatment $(P=0.012)$ (Table 2), suggesting that not all AR variants are equivalent in predicting clinical resistance and progression. Guo et al. (2009) assessed AR-V7 protein expression by immunohistochemistry in castration-resistant, $\mathrm{HN}$, and benign tumor samples. Nuclear AR-V7 staining was positive in $44 \%$ of castration-resistant samples compared with 9 and $0 \%$ in $\mathrm{HN}$ and benign samples respectively. This study further evaluated the predictive value of AR-V7, leading to the unexpected finding that high cytoplasmic staining of AR-V7 had a greater risk for PSA recurrence after radical prostatectomy $(P<0.0001)$, and high AR-V7 staining had the highest hazard ratio $(2.486, P<0.0043)$ for $\mathrm{PCa}$ recurrence (Fig. 2D and Table 2). The functional significance of AR-V7 cytoplasmic expression is not clear; particularly in light of the finding that AR-V7 has a functional NLS-like sequence that enhances efficient nuclear localization (Chan et al. 2012). In contrast to these studies that found AR variant levels were predictive of clinical outcome, a separate study that analyzed mRNA levels of AR-V1 and AR-V7 in surgical specimens using branched chain technology found that there was no association between AR variant expression and disease recurrence (Zhao et al. 2012). The difference in AR-V7 mRNA association with disease recurrence between this study and the study by Hu et al. (2009) could be due to the methods of measuring AR-V7 (branched chain vs RT-PCR) in prostate specimens.

There is evidence that AR variants are expressed at low mRNA levels relative to full-length AR in both benign and malignant epithelium. Although AR variants are detectable in benign/normal tissues, their possible functional roles in normal prostate physiology and embryogenesis or regeneration are not known. It is possible that $\mathrm{AR}$ variants may not play a role in driving tumor initiation, but instead play a specific functional role in driving tumor progression during ADT. In support of this hypothesis, analysis of AR-V12/AR ${ }^{\text {v567es }}$ and AR-V7 mRNA expression in metastatic samples from CRPC patients revealed that out of 46 AR-positive metastases, $43 \%$ expressed AR-V12/AR ${ }^{\mathrm{v} 567 \mathrm{es}}$ and 24\% expressed AR-V7 mRNA compared with 17 and $6 \%$ in normal tissue, respectively (Sun et al. 2010). Another study focusing on bone metastases found that full-length AR, AR-V7, and AR-V1 mRNAs were detected in $100 \%$ of samples ( $n=30$ bone metastases) and AR-V12/AR ${ }^{\mathrm{v} 567 \mathrm{es}}$ mRNA was detected in $23 \%$ of samples. AR-V1 and AR-V7 mRNAs were also detectable in nonmalignant prostate tissue, primary prostate tumors, and HN bone metastases. Nonetheless, both the number of AR variant positive samples and the mRNA levels of AR variants increased

Published by Bioscientifica Ltd. 

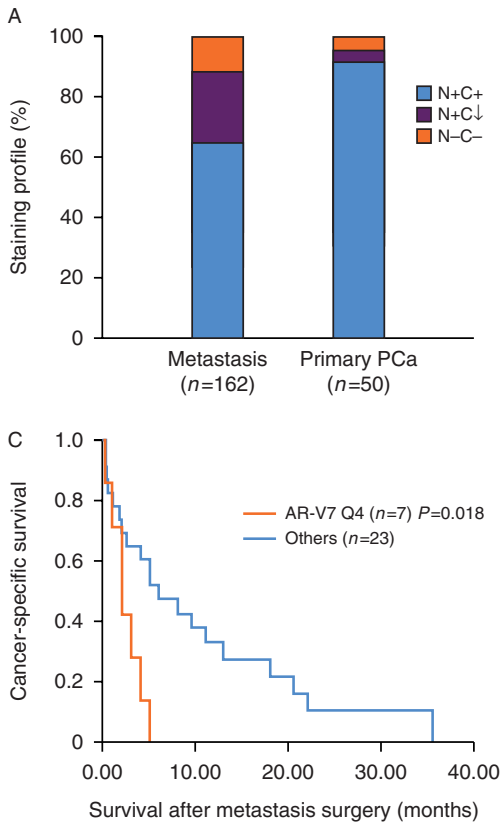

Figure 2

(A, B, C, and D) Clinical associations of AR variant expression. (A) Zhang et al. (2011) identified the AR protein levels using two AR-specific antibodies directed against the $\mathrm{N}$ - and $\mathrm{C}$-termini. This allowed for the inference of AR splice variant expression in these tissues, indicating that metastatic CRPC tissue contains a higher prevalence of $\mathrm{N}-\mathrm{C}$ - or $\mathrm{N}+\mathrm{C}$ reduced expression patterns as compared with localized disease (Zhang et al. 2011). (B) Using these same antibodies, Zhang et al. (2011) showed that PSA production by tumor cells appears to be reduced in some $\mathrm{N}+\mathrm{C}$ reduced tumors. (C) Hornberg et al. (2011) demonstrated through the

with disease progression (Table 2), and cancer-free survival after metastasis surgery was significantly shorter in patients with high AR-V7 mRNA expression (Fig. 2C; Hornberg et al. 2011). Finally, Zhang et al. (2011) measured variations in $\mathrm{N}$ - and $\mathrm{C}$-terminal $\mathrm{AR}$ expression in primary and metastatic PCa tissues and found a significant decrease in nuclear C-terminal AR staining relative to $\mathrm{N}$-terminal AR staining in metastatic samples, indicating the loss of full-length AR and enrichment for AR variants (Fig. 2A and B) during the metastatic process.

In summary, direct clinical evidence coupling $\mathrm{AR}$ variant function with PCa progression in large tissue collections is still being elucidated; however, the correlation between AR variant expression and CRPC is highly suggestive that these variants are selected to drive resistance during treatment. This notion is further supported by the existence of specific $A R$ gene rearrangements in clinical CRPC tissues that can cause AR variant expression and therapeutic resistance (Nyquist et al. 2013). Likewise, alternative AR-dependent and AR-independent
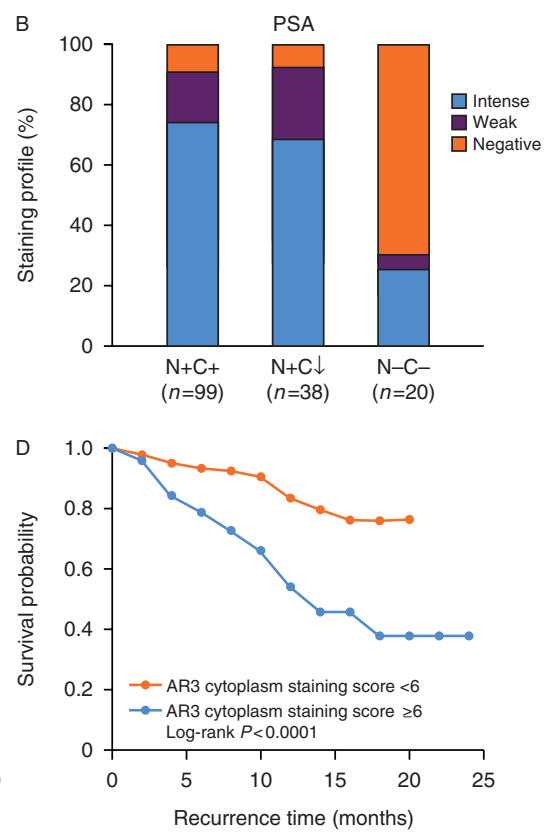

Kaplan-Meier analysis that high expression of AR-V7 in bone metastatic CRPC at surgery is associated with death from prostate cancer (PCa). (D) Guo et al. (2009) demonstrated a correlation of AR3 (AR-V7) cytoplasmic staining with PSA recurrence after prostatectomy. (D) Adapted, with permission, from the American Association for Cancer Research: Guo Z, Yang X, Sun F, Jiang R, Linn DE, Chen H, Kong X, Melamed J, Tepper CG, Kung HJ et al. 2009 A novel androgen receptor splice variant is upregulated during PCa progression and promotes androgen depletion-resistant growth. Cancer Research 69 2305-2313.

resistant mechanisms will also exist. No current data are available from clinical CRPC tissues wherein AR variant expression has been measured pre- and post-enzalutamide or abiraterone treatment, but phase II clinical trials (NCT01942837, NCT01503229, NCT01385293) are ongoing to directly address this subject. Based on the available data, it is clear that high levels of AR variant expression can confer resistance to second-generation antiandrogens and inhibitors targeting androgen synthesis, particularly when $A R$ gene rearrangements underlie this expression. However, it remains to be established whether AR variants can confer resistance when expressed at the low levels found in benign epithelium or HN PCa. A barrier to addressing this question is a lack of validated and reliable clinical laboratory assessments for individual AR variants on collected metastatic tumor tissue, circulating tumor cells (CTCs), or in circulating plasma RNA that may permit the longitudinal assessment of $\mathrm{AR}$ variant emergence and targeting in the clinic. 


\section{Biological functions of AR variants contributing to CRPC}

\section{Transcriptional programs}

The precise role of the AR variants in the progression of men with CRPC remains incomplete until interrogation of all possible AR variants can be performed using unbiased approaches and linked to outcomes independent of other known AR alterations and oncogenic events that drive CRPC. However, from model systems it is clear that the AR variants are capable of recapitulating the full-length $\mathrm{AR}$ transcriptional program in the absence of androgens or full-length AR (Hu et al. 2012, Liu et al. 2013b, Nyquist et al. 2013), and several studies have also identified transcriptional targets that may be distinct to AR variants (Sun et al. 2010, Hu et al. 2012, Liu et al. 2013b). For example, $\mathrm{Hu}$ et al. identified gene sets that were upregulated during overexpression of AR-V7 and AR-V12/AR ${ }^{\text {v567es }}$, including several cell-cycle-related genes. Additionally, AR-V7 expression correlated with expression of one of these cell-cycle genes, UBE2C, in prostate specimens biopsied after hormone therapy (Hu et al. 2012). These data suggest that $\mathrm{AR}$ variants mediate a distinct cell-cycle gene expression profile that is separate from full-length AR. In support of these data, several other studies have found upregulation of cell-cycle genes in samples with AR variant expression (Hornberg et al. 2011, Zhang et al. 2011, Liu et al. 2013b). However, induction of this set of cell-cycle-related genes might simply be an indicator of a pro-proliferative level of AR transcriptional output. For instance, one study found that full-length AR signaling was also able to stimulate a transcriptional signature enriched for the AR-V7 signature cell-cycle-related genes, but only at low, pro-proliferative androgen concentrations, while high, anti-proliferative androgen concentrations promoted a transcriptional signature that was negatively enriched for the cell-cycle gene set. Moreover, increasing levels of exogenous AR-V7 and AR-V12/AR ${ }^{\mathrm{v} 567 \text { es }}$ expression led to a similar dichotomy in positive and negative regulation of these cell-cycle genes (Li et al. 2013). Therefore, the strength of transcriptional output from full-length AR or AR variants appears to dictate whether this distinct set of cell-cyclerelated genes is activated or repressed. These findings may have importance, as they may indicate that therapies inhibiting the cell cycle and/or proliferation may be effective for the treatment of CRPC (Table 3).

In contrast to $\mathrm{AR}$ variants that display constitutive transcriptional activity, a plasma membrane-associated AR variant, AR8 (which we propose be termed AR-V15), is predicted to encode a protein containing only the NTD and a unique 33-amino acid C-terminus. AR8 increased

Table 3 Potential targets for AR variant-driven CRPC

\begin{tabular}{l} 
\\
\hline AR variants \\
Truncated AR variants \\
Enhancers of AR variant \\
activity \\
SRFS1, U2AF2 \\
PI3K/AKT \\
C-SrC \\
NFkB \\
SRC1 \\
AR variant independent \\
HSP90 \\
Inhibitors of AR variant \\
activity \\
DAB2IP \\
FOXO1 \\
Downstream AR variant \\
targets \\
RHOB \\
UBE2C
\end{tabular}

EMT

\begin{tabular}{|c|c|}
\hline Effect & Targets \\
\hline Activate & AR \\
\hline Activate upstream & AR cryptic exons \\
\hline Activate upstream & PI3K/AKT inhibitors \\
\hline Activate upstream & AKT inhibitors, c-Src inhibitors \\
\hline Activate upstream & NFkB inhibitors \\
\hline Co-activate & Growth factor receptors, Erk \\
\hline Inhibit upstream & HSP90/27 \\
\hline $\begin{array}{l}\text { Inhibit upstream } \\
\text { Inhibit upstream }\end{array}$ & $\begin{array}{l}\text { EZH2 inhibitors } \\
\text { AKT/PI3K }\end{array}$ \\
\hline $\begin{array}{l}\text { Target downstream } \\
\text { Target downstream }\end{array}$ & $\begin{array}{l}\text { Rho, GPCR } \\
\text { Cell-cycle checkpoint }\end{array}$ \\
\hline Target downstream & HDAC inhibitors \\
\hline
\end{tabular}

Compounds

EPI-001, compound 30, ASC-J9

Splice switching oligos, RON inhibitors BKM120, MK2206, GDC-0941, others MK2206, Dasatinib, PP2A activators Statins, bortezomib

Vandetanib, BVD-523

STA-9090, AT13387, OGX-427

E7438

BKM120, MK2206

Statins, Sulindac

ARQ 501, PD-0332991, CDK4/6 inhibitor, docetaxel, cabazitaxel

Vorinostat, N-cadherin antibodies, inhibition of stemness programs (Gli/Hedgehog, NOTCH), combination approaches, c-met inhibition, DAB2IP/EZH2 inhibitors, many others (see Bitting et al. (2014)) 
epidermal growth factor (EGF)-induced transcriptional activation of full length AR through the recruitment of AR to the plasma membrane for phosphorylation. This data suggest that AR8 may function in potentiating the AR transcriptional program in response to growth factors during ADT. Moreover, AR8-specific knockdown inhibited androgen-independent growth in cell lines and was expressed in both benign prostate and tumor samples. However, more clinical evidence is needed to signify the importance of AR8 in CRPC (Yang et al. 2011).

\section{AR variant induction of an epithelial-to-mesenchymal transition (EMT) and invasiveness}

In response to ADT, PCa xenografts have been found to display an acute and reversible upregulation of both mesenchymal markers (Sun et al. 2012) and AR variants (Watson et al. 2010, Hu et al. 2012). These studies, combined with evidence demonstrating increased AR variant expression in metastatic PCa specimens, suggest that there is a relationship between AR variant signaling and an EMT program. This epithelial plasticity may be critical for PCa metastatic dissemination and treatment resistance (Bitting et al. 2014). Additionally, the splicing factor SFRS1, which was identified to be important for AR-V7 splicing, is known to promote EMT by inducing splicing of a constitutively active isoform of macrophage stimulating 1 receptor (MST1R; aka RON1) (Ghigna et al. 2005). MST1R is known to be overexpressed in PCa and is involved in invasiveness and tumor-microenvironmental interactions in PCa progression (Gurusamy et al. 2013). It is tempting to speculate that AR variant synthesis and EMT are dual outcomes of an alternative splicing program induced by ADT that could be targeted in CRPC (Table 3). Alternatively, EMT may be important in AR-independent PCa (Tanaka et al. 2010), based on the inverse relationship observed between EMT biomarkers such as N-cadherin and $A R$ expression in CRPC metastatic specimens. Expression of EMT biomarkers is common in CTCs of men with metastatic CRPC, suggesting that this epithelial plasticity and upregulation of mesenchymal and stemness biomarker expression may be relatively common in lethal CRPC, regardless of AR activity (Armstrong et al. 2011).

In support of a possible link between AR variant signaling and EMT, AR variants have been implicated in driving a mesenchymal and invasive phenotype. For example, overexpression of AR variants Q640X and AR-V7 in LNCaP cells resulted in upregulation of $\mathrm{N}$-cadherin mRNA and protein compared with full-length $\mathrm{AR}$, and activation of full-length AR signaling reduced $\mathrm{N}$-cadherin expression
(Cottard et al. 2013). N-cadherin upregulation coincided with increased mRNA expression of several other mesenchymal markers, including vimentin, Snail, and ZEB1 in cells transfected with AR variants. However, downregulation of the epithelial marker E-cadherin was not observed (Cottard et al. 2013). Another study identified Ras homolog gene family member B (RHOB), a small GTPase, as a distinct target gene activated by a 'hybrid' AR variant, termed TC-AR, which was modeled after the Q640X mutant form of AR containing two copies of AR exon 3 (Tsai et al. 2012). Interestingly, RHOB increased migration and morphological changes in cells expressing TC-AR; however, it did not contribute to androgen-independent growth (Tsai et al. 2012). Given the role of Ras pathway overexpression in CRPC development and EMT biology (Taylor et al. 2010, Mulholland et al. 2012), future studies are needed to address the functional significance of increased mesenchymal markers on the metastatic potential of these cells. It is likely these cells will have increased tumorigenicity based on another recent preclinical study that generated a genetically engineered mouse model in which AR-V12/AR ${ }^{\text {v567es }}$ expression was under the control of the prostate-specific probasin promoter. Importantly, welldifferentiated prostate adenocarcinoma formed with high penetrance in $\mathrm{AR}-\mathrm{V} 12 / \mathrm{AR}^{\mathrm{v} 567 \mathrm{es}}$ mice and tumors expressed increased Twist and vimentin and decreased E-cadherin expression compared with normal epithelium of WT mice. This further supports the idea that EMT may be one of the mechanisms underlying the invasive phenotype of tumors expressing the AR-V12/AR ${ }^{\mathrm{v} 567 \mathrm{es}}$ variant (Liu et al. 2013a). Additionally, a genetically engineered mouse model expressing AR-V7 demonstrated a similar increase in mesenchymal markers, as well as stemness biomarkers in comparison with WT mice (Sun et al. 2013). In summary, expanding preclinical data demonstrates that AR variants activate traditional AR targets, and possibly additional distinct targets related to the cell cycle, cancer invasiveness, and EMT. These putative novel downstream targets of AR variant activation may represent therapeutic targets in CRPC (Table 3).

\section{Enhancers and inhibitors of AR variants}

Efforts are also underway to identify strategies to inhibit AR variant activity through the prevention of nuclear localization, dissociation from co-activators, or by enhancing AR degradation. AR pioneering factors and co-activators are numerous and have been reviewed extensively elsewhere (Shiota et al. 2011, van de Wijngaart et al. 2012). Recent studies have suggested important disease-relevant roles for

Published by Bioscientifica Ltd. 
ERG, PARP, RB, FOXA1, and EZH2 in the regulation of transcriptional activity of full-length AR (Sharma et al. 2010, Schiewer et al. 2012, Xu et al. 2012, Chen et al. 2013). These emerging data suggests a complex interplay between oncogenic signaling, epigenetic regulation, and AR activity, which may also extend to the activity of AR variants. Most $A R$ variants lack the canonical NLS in the AR hinge region. However, even with loss of the NLS, the NTD/DBD core common to all AR variants has an inherent property of localizing efficiently to the nucleus, although the precise mechanisms for this are not clear (Chan et al. 2012). For certain AR variants, such as AR-V12/AR ${ }^{\mathrm{v} 567 \mathrm{es}}$ and AR-V7, this inherent localization guided by the NTD/DBD core is further enhanced by their unique $\mathrm{COOH}$-terminal extensions that harbor the AR NLS or recapitulate NLSlike sequences. The loss of the AR LBD also disrupts the interaction of AR variants with the chaperone protein heat shock protein 90 (HSP90) in the cytoplasm. Studies involving HSP inhibitors have varied in their abilities to affect AR variant activity (Chan et al. 2012, Gillis et al. 2013, Shafi et al. 2013). In LNCaP cells engineered to overexpress AR-V7, two independent HSP90 inhibitors (Geldanamycin and MJC13) failed to inhibit AR variant stabilization or localization to the nucleus (Shafi et al. 2013). In an independent study, another HSP90 inhibitor (AUY922) failed to inhibit nuclear import of AR variants, and no AR variant:HSP90 complex could be detected. Surprisingly, despite the independence of AR variants from HSP90, cells lines positive for AR variants displayed growth sensitivity to the HSP90 inhibitor (Gillis et al. 2013). Moreover, overexpression of AR variants in LNCaP cells was not sufficient to render them resistant to the HSP90 inhibitor (Gillis et al. 2013). These data indicate that HSP90 inhibitors may have clinical application in CRPC (Table 3) that is independent of AR variant expression.

Activation of cell signaling pathways is known to result in phosphorylation of full-length $\mathrm{AR}$, affecting localization to the nucleus and transcriptional activation. Sorafenib is a multikinase inhibitor targeting $R A F, V E G F R$ and $P D G F R B$ that was previously shown to also target full-length AR signaling (Oh et al. 2012). When full-length AR or AR Q640X was expressed in AR-null PC3 cells, sorafenib treatment inhibited transcriptional activity of both full-length and AR Q640X via proteasomal degradation, with no effect on nuclear localization. Furthermore, sorafenib inhibited proliferation in both AR negative (DU145, PC3) and AR positive (LNCaP, 22Rv1) cells, with significantly more inhibition in AR positive cells (Zengerling et al. 2012). In further support of an important role for AR variant regulation by phosphorylation, a recent report found that DAB2IP is capable of preventing both full-length AR and AR variant nuclear localization through dual mechanisms of inhibiting c-src phosphorylation of AR S81 and PP2A-mediated S81 dephosphorylation (Wu et al. 2013). Importantly, loss of DAB2IP has been linked to invasive carcinoma in CRPC by suppressing RAS activity and EMT through NFkB in PCa (Chen et al. 2002, Min et al. 2010). These studies show that DAB2IP is an inhibitor of RAS signaling, EMT, full-length AR activity, and AR variant activity. Therefore, DAB2IP may serve as a potential therapeutic target for the treatment of CRPC. Planned studies of combined inhibition of AR signaling and EZH2, the prime inhibitor of DAB2IP, should address this complex functional interplay (Table 3).

An alternative strategy for inhibiting activity of fulllength $\mathrm{AR}$ as well as AR variants is to disrupt interactions between AR and specific co-activators and repressors. For instance, Nakka et al. (2013) demonstrated that peptides designed to block the interaction between AR and steroid receptor coactivator-1 (SRC1) inhibited the transcriptional activity of both full-length AR and AR-V7. Additionally, ectopic expression of SRC1 increased transcriptional activity of AR-V7, and SRC1-induced AR-V7 activity was inhibited by the expression of FOXO1 due to competition for binding the NTD of AR (Bohrer et al. 2013). Similarly, treatment of PCa cells with PI3K/AKT inhibitors mediated FOXO1 nuclear translocation leading to a reduction in AR-V7 activity. Moreover, in PTEN-null LNCaP cells, ectopic expression of PTEN reduced full-length and AR-V7 transcriptional activity to a low level similar to that achieved with PI3K/AKT inhibitors (Mediwala et al. 2013). These studies pinpoint FOXO1 as a potentially important inhibitor of AR activity that is targetable via the AKT pathway, and suggest strategies that could be used in the clinic to combat AR variant-driven CRPC (Table 3).

An additional pathway linked to enzalutamide resistance and AR variant expression is the NFkB pathway. NFkB2/p52 was shown to enhance AR transcriptional activity as well as boost AR variant expression. For example, overexpression of $\mathrm{NFkB} / \mathrm{p} 52$ increased AR-V7 expression in LNCaP cells, and knockdown of NFkB/p52 expression in 22Rv1 cells decreased mRNA and protein expression of multiple AR variants. In line with this, overexpression of NFkB/p52 in LNCaP cells increased survival following enzalutamide treatment and, cells treated chronically with enzalutamide expressed higher endogenous $\mathrm{NFkB} / \mathrm{p} 52$ than nontreated cells. Importantly, knockdown of either AR variant or NFkB expression increased sensitivity to enzalutamide treatment, suggesting NFkB

Published by Bioscientifica Ltd. 
mediates enzalutamide resistance via induction of $\mathrm{AR}$ variants (Nadiminty et al. 2013). These data suggest that NFkB inhibition may have a role in the treatment of AR variant driven CRPC (Table 3). Further studies are needed to characterize the expression and role of each of these pathways in enzalutamide and/or abiraterone acetate resistant metastatic CRPC, and the association of these pathways with AR variant levels.

Another transcriptional co-factor of AR, four-and-a-half LIM domains 2 (FHL2), was shown to co-activate specific AR targets when localized to the nucleus. FLH2 expression increased the transcriptional activity of full-length AR, AR-V7 and the calpain-cleaved AR variant, trAR. In addition, calpain cleavage of the cytoskeletal protein filamin induced nuclear localization of FLH2 leading to increased AR activation (McGrath et al. 2013). These data provide additional support for the hypothesis that calpain inhibition may have therapeutic benefit in PCa (Table 3). In addition, calpain-mediated cleavage of filamin can affect cytoskeleton organization that leads to increased motility (O'Connell et al. 2009). Therefore, increases in calpain activity could support metastatic CRPC by reorganizing the cytoskeleton to enhance cell motility and via promoting AR variant synthesis and activation.

\section{Opportunities for therapeutic targeting of AR variants}

All Food and Drug Administration (FDA)-approved therapeutic agents that target AR exert their action through the AR LBD, and in most cases, AR-dependent resistance emerges after therapy. The discovery of AR variants has highlighted the need for therapies that target AR through alternative mechanisms, such as inhibiting the NTD or by inducing AR degradation. A major question currently is whether AR variant-based progression is a predominant mechanism mediating CRPC or whether other mechanisms, including bypass of AR dependence and an AR-independent PC (ARIPC), are more common in CRPC progression. ARIPC certainly is known to emerge in CRPC, and may relate to the progression or transformation into neuroendocrine (NEPC) or small cell PCa (Beltran et al. 2011), or may relate to poorly differentiated CRPC in which AR bypass mechanisms are predominant. Currently, very little is known about ARIPC in the clinic outside of NEPC; however, the CRPC genome is complex, with a number of emerging targets linked to PI3K, Ras, epigenetics, DNA damage repair, and $\mathrm{Rb}$ pathways that have $\mathrm{AR}$ independent function (Berger et al. 2011). However, for AR-dependent, ligand-independent CRPC, strategies to target AR are likely to be successful based on the available evidence to date. However, it will be essential to develop companion diagnostics to determine which CRPC tumors remain AR driven in this setting before using novel AR inhibitors.

Currently, there are several agents being validated preclinically for their ability to inhibit AR variants. For example, EPI-001 was discovered in a screen designed to identify compounds capable of binding and inhibiting the AF-1 transactivation region in the AR NTD. The AF- 1 domain is important for binding many AR co-regulators, and is responsible for the majority of AR transcriptional activity. Binding of EPI-001 to the AR AF-1 region inhibits the ability of AR to interact with proteins such as CREB-binding protein (Andersen et al. 2010). Importantly, EPI-001 inhibited transcriptional activity of full-length AR and AR-V12/AR ${ }^{\mathrm{v} 567 \mathrm{es}}$ and decreased tumor growth significantly more than bicalutamide in VCaP xenografts (Myung et al. 2013).

Other AR inhibitors enhance AR degradation as a mechanism to block AR variant activity. For example, ASC-J9 selectively degrades AR protein by disrupting AR dimerization. In addition to reduced AR-AR interaction, ASC$\mathrm{J} 9$ was shown to inhibit AR nuclear localization and promote degradation of both full-length and AR-V7 in 22Rv1 cells (Lai et al. 2013). In addition, ASC-J9 suppressed growth of AR variant positive (22Rv1) and androgen-independent (C81 and C4-2) tumors in castrated mice (Yamashita et al. 2012). Lin et al. discovered ASC-J9 to be superior to bicalutamide and enzalutamide in both androgen-dependent and -independent PCa cells. Both bicalutamide and enzalutamide enhanced invasion in PCa cell lines through a transforming growth factor-beta (TGF- $\beta$ )/Smad3/MMP9 mechanism. In contrast, ASC-J9 treatment did not enhance the invasive capacity of these cells (Lin et al. 2013). Furthermore, in a co-culture system with PCa cells and macrophages, bicalutamide and enzalutamide promoted migration of macrophages to PCa cells and resulted in more invasive PCa cells. Importantly, ASC-J9 decreased growth, migration, and macrophage infiltration of PCa cells both in vitro and in vivo (Lin et al. 2013). Overall, these third generation AR inhibitors appear to have activity in preclinical models of ADT resistance, but their abilities to block CRPC driven by AR variants requires further evaluation. In addition, siRNA therapeutics directed against the NTD of AR or which promote splice switching toward full-length AR or dominant negative AR45 (Ahrens-Fath et al. 2005) may be a reasonable strategy in the clinic, provided delivery of siRNA molecules can be targeted in a tumor-specific manner (Table 3).

Finally, co-targeting strategies, whereby full-length AR is targeted with conventional agents concurrent with targeting of intermediates that may promote AR variant

Published by Bioscientifica Lto. 
production or nuclear translocation, or which reduce the transcriptional effectors of AR variants, are likely to be more effective clinical strategies (Table 3). For example, given the role of EZH2 and DAB2IP in the regulation of AR and AR variant activity, EZH2 inhibition with small molecule agents may be an avenue to reduce AR activity without necessarily promoting AR variant production. Inhibitors of cell-cycle regulators and proliferation are currently in the clinic in the form of docetaxel and cabazitaxel (a taxane); however, there is concern that the only mechanism of taxane benefit in CRPC is related to the microtubule nuclear transport of AR. If this is the case, it is predicted that CRPC tumors with AR variants lacking the microtubule or dynein binding domain may be resistant to taxanes, given their microtubule independent nuclear translocation (Darshan et al. 2011, Thadani-Mulero et al. 2012). Ongoing studies such as the TAXYNERGY phase II trial (NCT01718353) should be able to explore whether AR variant expression is linked to resistance to microtubule disruption with docetaxel or cabazitaxel in the clinic. Given the potential cell-cycle-specific genes activated by AR variants, cell-cycle inhibitors such as PD-0332991, a CDK4/6 inhibitor (Table 3), may be active in tumors driven by $\mathrm{AR}$ variants, and are entering trials in $\mathrm{Rb}$-intact men with metastatic PCa. PI3K, which is involved in the reciprocal regulation of AR activity, and is an inhibitor of the repressive action of FOXO1 on AR activity, may also be a reasonable target strategy when combined with AR inhibitors, and ongoing trials (NCT01385293) will address this combination approach. Finally, inhibition of EMT and epithelial plasticity in tumors driven by AR variants may also be a reasonable broad target for systemic therapy, and strategies in this venue have been recently discussed elsewhere (Bitting et al. 2014).

\section{Summary and future work}

In conclusion, AR variant expression appears to emerge in the clinic during CRPC progression and metastatic dissemination. If preclinical models are accurate, the switch from full-length AR to AR variant dominant clones would be selected for during enzalutamide and abiraterone acetate treatment in men with CRPC. However, evidence associating AR variant expression with resistance to enzalutamide and abiraterone acetate treatment is needed from ongoing clinical trials to further support the clinical relevance of AR variants. The association of AR variant expression with other therapies, including docetaxel and cabazitaxel given their putative AR-based transport mechanism, is imperative to study clinically. The anticipated early use of these systemic agents in the clinic may lead to the development of a high proportion of men with either ARIPC or AR variant-driven CRPC, which in both cases would represent 'androgenindependent' forms of the disease. To address this, several key areas of clinical and translational research will be the development of reliable AR and AR variant biomarkers in CRPC tissue or blood (circulating tumor cells (CTCs) or plasma) to measure AR and specific AR variant expression and activity, and the development of therapeutics effective against ARIPC and AR variant DNA binding and transcriptional activation. The clinical relevance of AR variants would undoubtedly be established through documenting clinical benefit with selective AR N-terminal or DBD inhibitors after failure of traditional hormonal therapies, and by the pre-treatment identification of loss-of-C-terminal ligandbinding domains in these patients with CRPC.

\section{Declaration of interest}

The authors declare that there is no conflict of interest that could be perceived as prejudicing the impartiality of the review.

\section{Funding}

We acknowledge grant support from Veridex postdoctoral training grant (K E Ware), National Cancer Institute grant R01 CA127727, (M A GarciaBlanco), Robert B Goergen Prostate Cancer Foundation Young Investigator Award (A J Armstrong), Department of Defense Physician Research Training Award W81XWH-10-1- 0483 (A J Armstrong). Studies in the Dehm Lab have been supported by the grants from the National Institutes of Health (R01 CA174777 to S M Dehm), an American Cancer Society Research Scholar Grant (RSG-12-031-01, to S M Dehm), and a Department of Defense Prostate Cancer Research Program New Investigator Award (W81XWH-101-0353, to S M Dehm). S M Dehm is a Masonic Scholar of the Masonic Cancer Center, University of Minnesota.

\section{Acknowledgements}

The authors thank Zhang et al. (2011), Hornberg et al. (2011) and Guo et al. (2009) for the studies contributing to Fig. 2.

\section{References}

Ahrens-Fath I, Politz O, Geserick C \& Haendler B 2005 Androgen receptor function is modulated by the tissue-specific AR45 variant. FEBS Journal 272 74-84. (doi:10.1111/j.1432-1033.2004.04395.x)

Andersen RJ, Mawji NR, Wang J, Wang G, Haile S, Myung JK, Watt K, Tam T, Yang YC, Banuelos CA et al. 2010 Regression of castrate-recurrent prostate cancer by a small-molecule inhibitor of the amino-terminus domain of the androgen receptor. Cancer Cell 17 535-546. (doi:10.1016/ j.ccr.2010.04.027)

Armstrong AJ, Marengo MS, Oltean S, Kemeny G, Bitting RL, Turnbull JD, Herold CI, Marcom PK, George DJ \& Garcia-Blanco MA 2011 Circulating tumor cells from patients with advanced prostate and breast cancer display both epithelial and mesenchymal markers. Molecular Cancer Research 9 997-1007. (doi:10.1158/1541-7786.MCR-10-0490) http://erc.endocrinology-journals.org DOI: $10.1530 /$ ERC-13-0470
(C) 2014 Society for Endocrinology Printed in Great Britain
Published by Bioscientifica Ltd 
Balbas MD, Evans MJ, Hosfield DJ, Wongvipat J, Arora VK, Watson PA, Chen Y, Greene GL, Shen Y \& Sawyers CL 2013 Overcoming mutationbased resistance to antiandrogens with rational drug design. eLife $\mathbf{2}$ e00499. (doi:10.7554/eLife.00499)

Beltran H, Rickman DS, Park K, Chae SS, Sboner A, MacDonald TY, Wang Y, Sheikh KL, Terry S, Tagawa ST et al. 2011 Molecular characterization of neuroendocrine prostate cancer and identification of new drug targets. Cancer Discovery 1 487-495. (doi:10.1158/2159-8290.CD-11-0130)

Berger MF, Lawrence MS, Demichelis F, Drier Y, Cibulskis K, Sivachenko AY, Sboner A, Esgueva R, Pflueger D, Sougnez C et al. 2011 The genomic complexity of primary human prostate cancer. Nature $\mathbf{4 7 0} 214-220$. (doi:10.1038/nature09744)

Bergerat JP \& Ceraline J 2009 Pleiotropic functional properties of androgen receptor mutants in prostate cancer. Human Mutation 30 145-157. (doi:10.1002/humu.20848)

Bitting RL, Schaeffer D, Somarelli JA, Garcia-Blanco MA \& Armstrong AJ 2014 The role of epithelial plasticity in prostate cancer dissemination and treatment resistance. Cancer Metastasis Reviews.

Bohrer LR, Liu P, Zhong J, Pan Y, Angstman J, Brand LJ, Dehm SM \& Huang H 2013 FOXO1 binds to the TAU5 motif and inhibits constitutively active androgen receptor splice variants. Prostate 73 1017-1027. (doi:10.1002/ pros.22649)

de Bono JS, Logothetis CJ, Molina A, Fizazi K, North S, Chu L, Chi KN, Jones RJ, Goodman OB Jr, Saad F et al. 2011 Abiraterone and increased survival in metastatic prostate cancer. New England Journal of Medicine 364 1995-2005. (doi:10.1056/NEJMoa1014618)

Cai C, He HH, Chen S, Coleman I, Wang H, Fang Z, Chen S, Nelson PS, Liu XS, Brown $\mathrm{M}$ et al. 2011 Androgen receptor gene expression in prostate cancer is directly suppressed by the androgen receptor through recruitment of lysine-specific demethylase 1. Cancer Cell 20 457-471. (doi:10.1016/j.ccr.2011.09.001)

Ceraline J, Erdmann E, Erbs P, Deslandres-Cruchant M, Jacqmin D, Duclos B, Klein-Soyer C, Dufour P \& Bergerat JP 2003 A yeast-based functional assay for the detection of the mutant androgen receptor in prostate cancer. European Journal of Endocrinology 148 99-110. (doi:10.1530/eje.0.1480099)

Chan SC, Li Y \& Dehm SM 2012 Androgen receptor splice variants activate androgen receptor target genes and support aberrant prostate cancer cell growth independent of canonical androgen receptor nuclear localization signal. Journal of Biological Chemistry 287 19736-19749. (doi:10.1074/jbc.M112.352930)

Chang KH, Li R, Kuri B, Lotan Y, Roehrborn CG, Liu J, Vessella R, Nelson PS, Kapur P, Guo X et al. 2013 A gain-of-function mutation in DHT synthesis in castration-resistant prostate cancer. Cell 154 1074-1084. (doi:10.1016/j.cell.2013.07.029)

Chen H, Pong RC, Wang Z \& Hsieh JT 2002 Differential regulation of the human gene DAB2IP in normal and malignant prostatic epithelia: cloning and characterization. Genomics 79 573-581. (doi:10.1006/ geno.2002.6739)

Chen CD, Welsbie DS, Tran C, Baek SH, Chen R, Vessella R, Rosenfeld MG \& Sawyers CL 2004 Molecular determinants of resistance to antiandrogen therapy. Nature Medicine 10 33-39. (doi:10.1038/nm972)

Chen Y, Chi P, Rockowitz S, Iaquinta PJ, Shamu T, Shukla S, Gao D, Sirota I, Carver BS, Wongvipat J et al. 2013 ETS factors reprogram the androgen receptor cistrome and prime prostate tumorigenesis in response to PTEN loss. Nature Medicine 19 1023-1029. (doi:10.1038/nm.3216)

Choi N, Zhang B, Zhang L, Ittmann M \& Xin L 2012 Adult murine prostate basal and luminal cells are self-sustained lineages that can both serve as targets for prostate cancer initiation. Cancer Cell 21 253-265. (doi:10. 1016/j.ccr.2012.01.005)

Clegg NJ, Wongvipat J, Joseph JD, Tran C, Ouk S, Dilhas A, Chen Y, Grillot K, Bischoff ED, Cai L et al. 2012 ARN-509: a novel antiandrogen for prostate cancer treatment. Cancer Research 72 1494-1503. (doi:10.1158/ 0008-5472.CAN-11-3948)

Coffey K \& Robson CN 2012 Regulation of the androgen receptor by posttranslational modifications. Journal of Endocrinology 215 221-237. (doi:10.1530/JOE-12-0238)
Cottard F, Asmane I, Erdmann E, Bergerat JP, Kurtz JE \& Ceraline J 2013 Constitutively active androgen receptor variants upregulate expression of mesenchymal markers in prostate cancer cells. PLoS ONE $\mathbf{8}$ e63466. (doi:10.1371/journal.pone.0063466)

Darshan MS, Loftus MS, Thadani-Mulero M, Levy BP, Escuin D, Zhou XK, Gjyrezi A, Chanel-Vos C, Shen R, Tagawa ST et al. 2011 Taxane-induced blockade to nuclear accumulation of the androgen receptor predicts clinical responses in metastatic prostate cancer. Cancer Research $\mathbf{7 1}$ 6019-6029. (doi:10.1158/0008-5472.CAN-11-1417)

Dehm SM, Schmidt LJ, Heemers HV, Vessella RL \& Tindall DJ 2008 Splicing of a novel androgen receptor exon generates a constitutively active androgen receptor that mediates prostate cancer therapy resistance. Cancer Research 68 5469-5477. (doi:10.1158/0008-5472.CAN-08-0594)

Freedland SJ, Humphreys EB, Mangold LA, Eisenberger M, Dorey FJ, Walsh PC \& Partin AW 2007 Death in patients with recurrent prostate cancer after radical prostatectomy: prostate-specific antigen doubling time subgroups and their associated contributions to all-cause mortality. Journal of Clinical Oncology 25 1765-1771. (doi:10.1200/JCO.2006.08.0572)

Garraway LA \& Sellers WR 2006 Lineage dependency and lineage-survival oncogenes in human cancer. Nature Reviews. Cancer 6 593-602. (doi:10.1038/nrc1947)

Ghigna C, Giordano S, Shen H, Benvenuto F, Castiglioni F, Comoglio PM, Green MR, Riva S \& Biamonti G 2005 Cell motility is controlled by SF2/ASF through alternative splicing of the Ron protooncogene. Molecular Cell 20 881-890. (doi:10.1016/j.molcel.2005.10.026)

Gillis JL, Selth LA, Centenera MM, Townley SL, Sun S, Plymate SR, Tilley WD \& Butler LM 2013 Constitutively-active androgen receptor variants function independently of the HSP90 chaperone but do not confer resistance to HSP90 inhibitors. Oncotarget 4 691-704.

Goldstein AS, Huang J, Guo C, Garraway IP \& Witte ON 2010 Identification of a cell of origin for human prostate cancer. Science 329 568-571. (doi:10.1126/science.1189992)

Gu W, Zhang F \& Lupski JR 2008 Mechanisms for human genomic rearrangements. PathoGenetics 1 4. (doi:10.1186/1755-8417-1-4)

Guo Z, Yang X, Sun F, Jiang R, Linn DE, Chen H, Kong X, Melamed J, Tepper CG, Kung HJ et al. 2009 A novel androgen receptor splice variant is upregulated during prostate cancer progression and promotes androgen depletion-resistant growth. Cancer Research 69 2305-2313. (doi:10.1158/0008-5472.CAN-08-3795)

Gurusamy D, Gray JK, Pathrose P, Kulkarni RM, Finkleman FD \& Waltz SE 2013 Myeloid-specific expression of Ron receptor kinase promotes prostate tumor growth. Cancer Research 73 1752-1763. (doi:10.1158/ 0008-5472.CAN-12-2474)

Haffner MC, Aryee MJ, Toubaji A, Esopi DM, Albadine R, Gurel B, Isaacs WB, Bova GS, Liu W, Xu J et al. 2010 Androgen-induced TOP2B-mediated double-strand breaks and prostate cancer gene rearrangements. Nature Genetics 42 668-675. (doi:10.1038/ng.613)

Han G, Foster BA, Mistry S, Buchanan G, Harris JM, Tilley WD \& Greenberg NM 2001 Hormone status selects for spontaneous somatic androgen receptor variants that demonstrate specific ligand and cofactor dependent activities in autochthonous prostate cancer. Journal of Biological Chemistry 276 11204-11213. (doi:10.1074/jbc.M008207200)

Hastings PJ, Ira G \& Lupski JR 2009 A microhomology-mediated breakinduced replication model for the origin of human copy number variation. PLoS Genetics 5 e1000327. (doi:10.1371/journal.pgen. 1000327)

Hornberg E, Ylitalo EB, Crnalic S, Antti H, Stattin P, Widmark A, Bergh A \& Wikstrom P 2011 Expression of androgen receptor splice variants in prostate cancer bone metastases is associated with castration-resistance and short survival. PLOS ONE 6 e19059. (doi:10.1371/journal.pone. 0019059)

Hu R, Dunn TA, Wei S, Isharwal S, Veltri RW, Humphreys E, Han M, Partin AW, Vessella RL, Isaacs WB et al. 2009 Ligand-independent androgen receptor variants derived from splicing of cryptic exons signify hormone-refractory prostate cancer. Cancer Research 69 16-22. (doi:10.1158/0008-5472.CAN-08-2764) 
$\mathrm{Hu}$ R, Isaacs WB \& Luo J 2011 A snapshot of the expression signature of androgen receptor splicing variants and their distinctive transcriptional activities. Prostate 71 1656-1667. (doi:10.1002/pros.21382)

Hu R, Lu C, Mostaghel EA, Yegnasubramanian S, Gurel M, Tannahill C, Edwards J, Isaacs WB, Nelson PS, Bluemn E et al. 2012 Distinct transcriptional programs mediated by the ligand-dependent full-length androgen receptor and its splice variants in castration-resistant prostate cancer. Cancer Research 72 3457-3462. (doi:10.1158/0008-5472.CAN-11-3892)

Hussain M, Tangen CM, Higano C, Schelhammer PF, Faulkner J, Crawford ED, Wilding G, Akdas A, Small EJ, Donnelly B et al. 2006 Absolute prostate-specific antigen value after androgen deprivation is a strong independent predictor of survival in new metastatic prostate cancer: data from Southwest Oncology Group Trial 9346 (INT-0162). Journal of Clinical Oncology 24 3984-3990. (doi:10.1200/JCO.2006.06.4246)

Joseph JD, Lu N, Qian J, Sensintaffar J, Shao G, Brigham D, Moon M, Maneval EC, Chen I, Darimont B et al. 2013 A clinically relevant androgen receptor mutation confers resistance to second-generation antiandrogens enzalutamide and ARN-509. Cancer Discovery 3 1020-1029. (doi:10.1158/2159-8290.CD-13-0226)

Joung JK \& Sander JD 2013 TALENs: a widely applicable technology for targeted genome editing. Nature Reviews. Molecular Cell Biology 14 49-55. (doi:10.1038/nrm3486)

Korpal M, Korn JM, Gao X, Rakiec DP, Ruddy DA, Doshi S, Yuan J, Kovats SG, Kim S, Cooke VG et al. 2013 An F876L mutation in androgen receptor confers genetic and phenotypic resistance to MDV3100 (Enzalutamide). Cancer Discovery 3 1030-1043. (doi:10.1158/2159-8290.CD-13-0142)

Koumbaris G, Hatzisevastou-Loukidou H, Alexandrou A, Ioannides M, Christodoulou C, Fitzgerald T, Rajan D, Clayton S, Kitsiou-Tzeli S, Vermeesch JR et al. 2011 FoSTeS, MMBIR and NAHR at the human proximal $\mathrm{Xp}$ region and the mechanisms of human $\mathrm{Xq}$ isochromosome formation. Human Molecular Genetics 20 1925-1936. (doi:10.1093/hmg/ddr074)

Lai KP, Huang CK, Chang YJ, Chung CY, Yamashita S, Li L, Lee SO, Yeh S \& Chang C 2013 New therapeutic approach to suppress castrationresistant prostate cancer using ASC-J9 via targeting androgen receptor in selective prostate cells. American Journal of Pathology 182 460-473. (doi:10.1016/j.ajpath.2012.10.029)

Li Y, Alsagabi M, Fan D, Bova GS, Tewfik AH \& Dehm SM 2011 Intragenic rearrangement and altered RNA splicing of the androgen receptor in a cell-based model of prostate cancer progression. Cancer Research $\mathbf{7 1}$ 2108-2117. (doi:10.1158/0008-5472.CAN-10-1998)

Li Y, Hwang TH, Oseth LA, Hauge A, Vessella RL, Schmechel SC, Hirsch B, Beckman KB, Silverstein KA \& Dehm SM 2012 AR intragenic deletions linked to androgen receptor splice variant expression and activity in models of prostate cancer progression. Oncogene 31 4759-4767. (doi:10. 1038/onc.2011.637)

Li Y, Chan SC, Brand LJ, Hwang TH, Silverstein KA \& Dehm SM 2013 Androgen receptor splice variants mediate enzalutamide resistance in castration-resistant prostate cancer cell lines. Cancer Research $\mathbf{7 3}$ 483-489. (doi:10.1158/0008-5472.CAN-12-3630)

Libertini SJ, Tepper CG, Rodriguez V, Asmuth DM, Kung HJ \& Mudryj M 2007 Evidence for calpain-mediated androgen receptor cleavage as a mechanism for androgen independence. Cancer Research $\mathbf{6 7}$ 9001-9005. (doi:10.1158/0008-5472.CAN-07-1072)

Lin C, Yang L, Tanasa B, Hutt K, Ju BG, Ohgi K, Zhang J, Rose DW, Fu XD, Glass CK et al. 2009 Nuclear receptor-induced chromosomal proximity and DNA breaks underlie specific translocations in cancer. Cell 139 1069-1083. (doi:10.1016/j.cell.2009.11.030)

Lin TH, Izumi K, Lee SO, Lin WJ, Yeh S \& Chang C 2013 Anti-androgen receptor ASC-J9 versus anti-androgens MDV3100 (Enzalutamide) or Casodex (Bicalutamide) leads to opposite effects on prostate cancer metastasis via differential modulation of macrophage infiltration and STAT3-CCL2 signaling. Cell Death \& Disease 4 e764. (doi:10.1038/cddis.2013.270)

Liu G, Sprenger C, Sun S, Epilepsia KS, Haugk K, Zhang X, Coleman I, Nelson PS \& Plymate S 2013a AR variant AR(v567es) induces carcinogenesis in a novel transgenic mouse model of prostate cancer. Neoplasia 15 1009-1017.
Liu LL, Xie N, Sun S, Plymate S, Mostaghel E \& Dong X 2013b Mechanisms of the androgen receptor splicing in prostate cancer cells. Oncogene.

Loriot Y, Bianchini D, Ileana E, Sandhu S, Patrikidou A, Pezaro C, Albiges L, Attard G, Fizazi K, De Bono JS et al. 2013 Antitumour activity of abiraterone acetate against metastatic castration-resistant prostate cancer progressing after docetaxel and enzalutamide (MDV3100). Annals of Oncology 24 1807-1812. (doi:10.1093/annonc/mdt136)

Mani RS, Tomlins SA, Callahan K, Ghosh A, Nyati MK, Varambally S, Palanisamy N \& Chinnaiyan AM 2009 Induced chromosomal proximity and gene fusions in prostate cancer. Science 326 1230. (doi:10. 1126/science.1178124)

McGrath MJ, Binge LC, Sriratana A, Wang H, Robinson PA, Pook D, Fedele CG, Brown S, Dyson JM, Cottle DL et al. 2013 Regulation of the transcriptional coactivator FHL2 licenses activation of the androgen receptor in castrate-resistant prostate cancer. Cancer Research $\mathbf{7 3}$ 5066-5079. (doi:10.1158/0008-5472.CAN-12-4520)

Mediwala SN, Sun H, Szafran AT, Hartig SM, Sonpavde G, Hayes TG, Thiagarajan P, Mancini MA \& Marcelli M 2013 The activity of the androgen receptor variant AR-V7 is regulated by FOXO1 in a PTEN-PI3KAKT-dependent way. Prostate 73 267-277. (doi:10.1002/pros.22566)

Min J, Zaslavsky A, Fedele G, McLaughlin SK, Reczek EE, De Raedt T, Guney I, Strochlic DE, Macconaill LE, Beroukhim R et al. 2010 An oncogenetumor suppressor cascade drives metastatic prostate cancer by coordinately activating Ras and nuclear factor- $\kappa \mathrm{B}$. Nature Medicine 16 286-294. (doi:10.1038/nm.2100)

Mostaghel EA, Marck BT, Plymate SR, Vessella RL, Balk S, Matsumoto AM, Nelson PS \& Montgomery RB 2011 Resistance to CYP17A1 inhibition with abiraterone in castration-resistant prostate cancer: induction of steroidogenesis and androgen receptor splice variants. Clinical Cancer Research 17 5913-5925. (doi:10.1158/1078-0432.CCR-11-0728)

Mulholland DJ, Kobayashi N, Ruscetti M, Zhi A, Tran LM, Huang J, Gleave M \& Wu H 2012 Pten loss and RAS/MAPK activation cooperate to promote EMT and metastasis initiated from prostate cancer stem/progenitor cells. Cancer Research 72 1878-1889. (doi:10.1158/0008-5472.CAN-11-3132)

Myung JK, Banuelos CA, Fernandez JG, Mawji NR, Wang J, Tien AH, Yang YC, Tavakoli I, Haile S, Watt K et al. 2013 An androgen receptor N-terminal domain antagonist for treating prostate cancer. Journal of Clinical Investigation 123 2948-2960. (doi:10.1172/JCI66398)

Nadiminty N, Tummala R, Liu C, Yang J, Lou W, Evans CP \& Gao AC 2013 $\mathrm{NF}-\kappa \mathrm{B} 2 / \mathrm{p} 52$ induces resistance to enzalutamide in prostate cancer: role of androgen receptor and its variants. Molecular Cancer Therapeutics 12 1629-1637. (doi:10.1158/1535-7163.MCT-13-0027)

Nakka M, Agoulnik IU \& Weigel NL 2013 Targeted disruption of the p160 coactivator interface of androgen receptor (AR) selectively inhibits AR activity in both androgen-dependent and castration-resistant AR-expressing prostate cancer cells. International Journal of Biochemistry \& Cell Biology 45 763-772. (doi:10.1016/j.biocel.2012.12.012)

Noonan KL, North S, Bitting RL, Armstrong AJ, Ellard SL \& Chi KN 2013 Clinical activity of abiraterone acetate in patients with metastatic castration-resistant prostate cancer progressing after enzalutamide. Annals of Oncology 24 1802-1807. (doi:10.1093/annonc/mdt138)

Nyquist MD, Li Y, Hwang TH, Manlove LS, Vessella RL, Silverstein KA, Voytas DF \& Dehm SM 2013 TALEN-engineered AR gene rearrangements reveal endocrine uncoupling of androgen receptor in prostate cancer. PNAS 110 17492-17497.

O'Connell MP, Fiori JL, Baugher KM, Indig FE, French AD, Camilli TC, Frank BP, Earley R, Hoek KS, Hasskamp JH et al. 2009 Wnt5A activates the calpain-mediated cleavage of filamin A. Journal of Investigative Dermatology 129 1782-1789. (doi:10.1038/jid.2008.433)

Oh SJ, Erb HH, Hobisch A, Santer FR \& Culig Z 2012 Sorafenib decreases proliferation and induces apoptosis of prostate cancer cells by inhibition of the androgen receptor and Akt signaling pathways. Endocrine-Related Cancer 19 305-319. (doi:10.1530/ERC-11-0298)

Rios-Doria J, Kuefer R, Ethier SP \& Day ML 2004 Cleavage of $\beta$-catenin by calpain in prostate and mammary tumor cells. Cancer Research 64 7237-7240. (doi:10.1158/0008-5472.CAN-04-1048) 
Ryan CJ, Smith MR, de Bono JS, Molina A, Logothetis CJ, de Souza P, Fizazi K, Mainwaring P, Piulats JM, Ng S et al. 2013 Abiraterone in metastatic prostate cancer without previous chemotherapy. New England Journal of Medicine 368 138-148. (doi:10.1056/NEJMoa1209096)

Schaeffer AJ 2013 Editorial comment. Urology 81 555-556 discussion 556. (doi:10.1016/j.urology.2012.10.062)

Scher HI, Beer TM, Higano CS, Anand A, Taplin ME, Efstathiou E, Rathkopf D, Shelkey J, Yu EY, Alumkal J et al. 2010 Antitumour activity of MDV3100 in castration-resistant prostate cancer: a phase 1-2 study. Lancet $\mathbf{3 7 5}$ 1437-1446. (doi:10.1016/S0140-6736(10)60172-9)

Scher HI, Fizazi K, Saad F, Taplin ME, Sternberg CN, Miller K, de Wit R, Mulders P, Chi KN, Shore ND et al. 2012 Increased survival with enzalutamide in prostate cancer after chemotherapy. New England Journal of Medicine 367 1187-1197. (doi:10.1056/NEJMoa1207506)

Schiewer MJ, Goodwin JF, Han S, Brenner JC, Augello MA, Dean JL, Liu F, Planck JL, Ravindranathan P, Chinnaiyan AM et al. 2012 Dual roles of PARP-1 promote cancer growth and progression. Cancer Discovery 2 1134-1149. (doi:10.1158/2159-8290.CD-12-0120)

Shafi AA, Cox MB \& Weigel NL 2013 Androgen receptor splice variants are resistant to inhibitors of Hsp90 and FKBP52, which alter androgen receptor activity and expression. Steroids $\mathbf{7 8} 548-554$. (doi:10.1016/ j.steroids.2012.12.013)

Sharma A, Yeow WS, Ertel A, Coleman I, Clegg N, Thangavel C, Morrissey C, Zhang X, Comstock CE, Witkiewicz AK et al. 2010 The retinoblastoma tumor suppressor controls androgen signaling and human prostate cancer progression. Journal of Clinical Investigation $1204478-4492$. (doi:10.1172/JCI44239)

Shiota M, Yokomizo A, Fujimoto N \& Naito S 2011 Androgen receptor cofactors in prostate cancer: potential therapeutic targets of castrationresistant prostate cancer. Current Cancer Drug Targets 11 870-881. (doi:10.2174/156800911796798904)

Siegel RD 2013 American Society of Clinical Oncology Quality Care Symposium 2012: re-engineering your practice to deliver quality and value. Journal of Oncology Practice 9 160-161. (doi:10.1200/JOP.2013.000925)

Stanbrough M, Bubley GJ, Ross K, Golub TR, Rubin MA, Penning TM, Febbo PG \& Balk SP 2006 Increased expression of genes converting adrenal androgens to testosterone in androgen-independent prostate cancer. Cancer Research 66 2815-2825. (doi:10.1158/0008-5472.CAN-05-4000)

Sun S, Sprenger CC, Vessella RL, Haugk K, Soriano K, Mostaghel EA, Page ST, Coleman IM, Nguyen HM, Sun H et al. 2010 Castration resistance in human prostate cancer is conferred by a frequently occurring androgen receptor splice variant. Journal of Clinical Investigation 120 2715-2730. (doi:10.1172/JCI41824)

Sun Y, Wang BE, Leong KG, Yue P, Li L, Jhunjhunwala S, Chen D, Seo K, Modrusan Z, Gao WQ et al. 2012 Androgen deprivation causes epithelial-mesenchymal transition in the prostate: implications for androgen-deprivation therapy. Cancer Research 72 527-536. (doi:10. 1158/0008-5472.CAN-11-3004)

Sun F, Chen HG, Li W, Yang X, Wang X, Jiang R, Guo Z, Chen H, Huang J, Borowsky AD et al. 2013 Androgen receptor splice variant AR3 promotes prostate cancer via modulating expression of autocrine/ paracrine factors. Journal of Biological Chemistry 289 1529-1539. (doi:10.1074/jbc.M113.492140)

Tanaka H, Kono E, Tran CP, Miyazaki H, Yamashiro J, Shimomura T, Fazli L, Wada R, Huang J, Vessella RL et al. 2010 Monoclonal antibody targeting of $\mathrm{N}$-cadherin inhibits prostate cancer growth, metastasis and castration resistance. Nature Medicine 16 1414-1420. (doi:10.1038/nm.2236)

Taylor BS, Schultz N, Hieronymus H, Gopalan A, Xiao Y, Carver BS, Arora VK, Kaushik P, Cerami E, Reva B et al. 2010 Integrative genomic profiling of human prostate cancer. Cancer Cell 18 11-22. (doi:10.1016/j.ccr.2010. 05.026)

Tepper CG, Boucher DL, Ryan PE, Ma AH, Xia L, Lee LF, Pretlow TG \& Kung HJ 2002 Characterization of a novel androgen receptor mutation in a relapsed CWR22 prostate cancer xenograft and cell line. Cancer Research 62 6606-6614.

Thadani-Mulero M, Nanus DM \& Giannakakou P 2012 Androgen receptor on the move: boarding the microtubule expressway to the nucleus. Cancer Research 72 4611-4615. (doi:10.1158/0008-5472.CAN-12-0783)

Tran C, Ouk S, Clegg NJ, Chen Y, Watson PA, Arora V, Wongvipat J, SmithJones PM, Yoo D, Kwon A et al. 2009 Development of a secondgeneration antiandrogen for treatment of advanced prostate cancer. Science 324 787-790. (doi:10.1126/science.1168175)

Tsai HC, Boucher DL, Martinez A, Tepper CG \& Kung HJ 2012 Modeling truncated AR expression in a natural androgen responsive environment and identification of RHOB as a direct transcriptional target. PLOS ONE 7 e49887. (doi:10.1371/journal.pone.0049887)

Wang X, Kruithof-de Julio M, Economides KD, Walker D, Yu H, Halili MV, $\mathrm{Hu}$ YP, Price SM, Abate-Shen C \& Shen MM 2009 A luminal epithelial stem cell that is a cell of origin for prostate cancer. Nature $\mathbf{4 6 1} 495-500$. (doi:10.1038/nature08361)

Wang ZA, Mitrofanova A, Bergren SK, Abate-Shen C, Cardiff RD, Califano A \& Shen MM 2013 Lineage analysis of basal epithelial cells reveals their unexpected plasticity and supports a cell-of-origin model for prostate cancer heterogeneity. Nature Cell Biology 15 274-283. (doi:10.1038/ncb2697)

Watson PA, Chen YF, Balbas MD, Wongvipat J, Socci ND, Viale A, Kim K \& Sawyers CL 2010 Constitutively active androgen receptor splice variants expressed in castration-resistant prostate cancer require full-length androgen receptor. PNAS 107 16759-16765. (doi:10.1073/pnas.1012443107)

Weischenfeldt J, Simon R, Feuerbach L, Schlangen K, Weichenhan D, Minner S, Wuttig D, Warnatz HJ, Stehr H, Rausch T et al. 2013 Integrative genomic analyses reveal an androgen-driven somatic alteration landscape in early-onset prostate cancer. Cancer Cell $\mathbf{2 3}$ 159-170. (doi:10.1016/j.ccr.2013.01.002)

van de Wijngaart DJ, Dubbink HJ, van Royen ME, Trapman J \& Jenster G 2012 Androgen receptor coregulators: recruitment via the coactivator binding groove. Molecular and Cellular Endocrinology 352 57-69. (doi:10. 1016/j.mce.2011.08.007)

Wu K, Liu J, Tseng SF, Gore C, Ning Z, Sharifi N, Fazli L, Gleave M, Kapur P, Xiao $\mathrm{G}$ et al. 2013 The role of DAB2IP in androgen receptor activation during prostate cancer progression. Oncogene.

Xu K, Wu ZJ, Groner AC, He HH, Cai C, Lis RT, Wu X, Stack EC, Loda M, Liu T et al. $2012 \mathrm{EZH} 2$ oncogenic activity in castration-resistant prostate cancer cells is Polycomb-independent. Science 338 1465-1469. (doi:10.1126/science.1227604)

Yamashita S, Lai KP, Chuang KL, Xu D, Miyamoto H, Tochigi T, Pang ST, Li L, Arai Y, Kung HJ et al. 2012 ASC-J9 suppresses castration-resistant prostate cancer growth through degradation of full-length and splice variant androgen receptors. Neoplasia 14 74-83.

Yang X, Guo Z, Sun F, Li W, Alfano A, Shimelis H, Chen M, Brodie AM, Chen H, Xiao Z et al. 2011 Novel membrane-associated androgen receptor splice variant potentiates proliferative and survival responses in prostate cancer cells. Journal of Biological Chemistry 286 36152-36160. (doi:10.1074/jbc.M111.265124)

Zengerling F, Streicher W, Schrader AJ, Schrader M, Nitzsche B, Cronauer MV \& Hopfner M 2012 Effects of sorafenib on C-terminally truncated androgen receptor variants in human prostate cancer cells. International Journal of Molecular Sciences 13 11530-11542. (doi:10.3390/ijms130911530)

Zhang X, Morrissey C, Sun S, Ketchandji M, Nelson PS, True LD, VakarLopez F, Vessella RL \& Plymate SR 2011 Androgen receptor variants occur frequently in castration resistant prostate cancer metastases. PLoS ONE 6 e27970. (doi:10.1371/journal.pone.0027970)

Zhao H, Coram MA, Nolley R, Reese SW, Young SR \& Peehl DM 2012 Transcript levels of androgen receptor variant AR-V1 or AR-V7 do not predict recurrence in patients with prostate cancer at indeterminate risk for progression. Journal of Urology 188 2158-2164. (doi:10.1016/j.juro. 2012.08.014)

Received in final form 11 January 2014

Accepted 23 January 2014 http://erc.endocrinology-journals.org

DOI: 10.1530/ERC-13-0470
(C) 2014 Society for Endocrinology Printed in Great Britain
Published by Bioscientifica Ltd. 